\title{
Collateral Risk, Repo Rollover and Shadow Banking
}

\author{
Shengxing Zhang*† \\ Department of Economics, New York University \\ [download the latest version]
}

January 26, 2014

\begin{abstract}
I build a dynamic model of the shadow banking system and the interbank repo market to understand their efficiency and stability. The model emphasizes a key friction: the maturity mismatch between short-term repo and long-term investments that banks need to finance. The haircut, interest rate, and default rate of the repo contract are endogenously determined in the model, as are the volume of lending and liquidity hoarding. Default is shown to be contagious. Finally, when collateral risk increases unexpectedly, the haircut and interest rate overshoot, triggering massive defaults and persistently hiking the default rate and depressing investment.
\end{abstract}

*email: shengxing.zhang@nyu.edu

${ }^{\dagger} \mathrm{I}$ am indebted to Ricardo Lagos, Douglas Gale, Boyan Jovanovic and Thomas Sargent for their support and discussions. I am especially grateful to Ricardo Lagos and Douglas Gale for their guidance on the project. I also thank David Andolfatto, Gara Afonso, Saki Bigio, Dan Cao, Katarína Borovička, Jaroslav Borovička, Emmanuel Farhi, Klaus-Peter Hellwig, Ben Lester, Yaron Leitner, Jesse Perla, Edouard Schaal, Cecilia Parlatore Siritto, Chris Tonetti, Laura Veldkamp, Venky Venkateswaran, Gianluca Violante and all other participants of the Sargent Research Group, the Student Macro Lunch seminar of the Department of Economics at New York University, the Macro Lunch seminar at NYU Stern, the student workshop at Wharton and the brown bag seminar at the Federal Reserve Bank of St. Louis. 


\section{Introduction}

The shadow banking system is an essential part of the process of credit creation in modern banking. ${ }^{1}$ The process relies heavily on short-term debt instruments such as repurchase contracts (repo), a short-term collateralized debt contract with safe harbor provisions. ${ }^{2}$ Just before the great recession, the gross volume of outstanding repo contracts reached $\$ 10$ trillion in both the US and Euro-zone repo markets. To put this amount into perspective, it amounted about $70 \%$ of GDP in the respective areas in $2007 .^{3}$

In 2007, the risk on collateral assets increased unexpectedly due to the sharp decline in housing prices. ${ }^{4}$ Concerned about the quality of collateral assets, financial intermediaries reduced their repo exposure to each other and began hoarding liquidity. The haircut and interest rates shot up. This eventually led to the downfall of Lehman Brothers, which ran out of resources to finance its long-term investments. ${ }^{5}$

The crisis in the repo market and the shadow banking system exposed the instability of the system and left us with the following questions. What is the source of systemic risk in the shadow banking system? Are the efficiency and stability of the system affected by frictions in the repo market? What triggered the crisis? Why has the system not fully recovered even five years after the outbreak of the crisis?

To answer these questions, I build a dynamic model of the shadow banking system and the interbank repo market. Banks have an initial endowment of cash and collateral. Each bank anticipates an investment option that arrives according to a Poisson process. While a bank waits for its investment option to arrive, it lends through the repo market to banks that already have an

\footnotetext{
${ }^{1}$ See Pozsar et al. [2013] for the credit intermediation process in the shadow banking system. And I will explain its institutional features in more detail in the next section.

${ }^{2}$ In legal terms, a repo contract is a combination of two outright transactions, sales at the moment the contract is signed and purchase at a future date at a price according to the contract. Since it can be interpreted either as a combination of two spot trades or as a secured loan, it helps some financial institutions circumvent legal restrictions to lending to other institutions or to carrying out spot trade. Another difference between the repo contract and a secured loan is that when a borrower defaults, the collateral asset is not subject to automatic stay. The safe harbor provision makes financing through a repo contract popular. See Garbade [2006] for more details.

${ }^{3}$ See Hördahl and King [2008].

${ }^{4} \mathrm{ABX}$ indices, price index for CDS over a collection of mortgage backed securities, dropped.

${ }^{5}$ Gorton [2009] gives a detailed description of the unfolding of the events in the crisis.
} 
investment opportunity. The model emphasizes a key friction: the maturity mismatch between the short-term repo and the long-term investment that banks need to finance. The maturity mismatch results in borrowers having to roll over their debt until the investment matures and they are able to repay their loan. If the investment does not mature before the borrower reaches his (endogenous) debt limit, the borrower will be forced to default.

The haircut, interest rate and default rate of the repo contract are all endogenously determined in the model. As we will see, the endogenous haircut and default rate allow me to study how changes in the primitives of the model affect the borrowing constraint and the externalities caused by default.

I show that systemic risk arises because default triggers more default. When a borrower defaults, the lender's portfolio becomes less liquid: she gains a collateral asset but loses her claim to future cash from her counterparty. Then, when the lender's investment opportunity arrives, she relies more on secured borrowing (backed by the collateral assets) and less on her own cash. This makes her more likely to default because, other things being equal, she reaches her debt limit faster. Thus, counterparty default is contagious.

To understand the failure of the shadow banking system and to check the robustness of the theory, I extend the model to allow for collateral risk $^{6}$ and find that an increase in collateral risk increases counterparty default risk. When collateral risk increases, the repo market dries up through two channels, liquidity hoarding and counterparty default. Banks reduce funding to the repo market and hoard more liquidity to secure funding for their own investment in the future. With less funding in the repo market, the equilibrium haircut and interest rate increase, the debt limit is reached faster, and default is more likely. Counterparty default transforms the lenders' portfolios and further decreases the supply of funding to the repo market. So, as collateral risk increases, the efficiency of the financial system declines.

I use the dynamic model to study both the efficiency of the shadow banking system in the steady state and the stability of the system in response to an unanticipated shock. The stability of the system can be measured by two metrics: the magnitude of the initial response and the persistence

\footnotetext{
${ }^{6}$ At the time, $50 \%$ of primary broker-dealers' repo contracts are backed by such less-liquid securities as corporate securities, mortgage-backed securities and other asset-backed securities, and $65 \%$ of the contracts are overnight. See Adrian et al. [2009].
} 
of the efficiency loss on the transition path to the new steady state. My objective is to understand the stability of the financial system at the onset of the great recession. To do this, I characterize the transition dynamics triggered by an unexpected increase in collateral risk. On impact, the hoarding motive of lenders imposes a downward pressure on the supply of funds to the repo market. As a result, both the haircut and interest rate increase sharply to clear the market. This leads to a tightening of the borrowers' debt limit and a massive default by those borrowers who suddenly find themselves over their debt limit. In addition, the rest of the borrowers who started borrowing before the crisis now face a debt overhang problem, which increases the default rate from that point onward. Since counterparty default is contagious, the massive initial default and the increase in the default rate have a persistent effect on the equilibrium path: Repo lending and investment remain low, and the default rate remains high for an extended period of time. The systemic risk from contagious counterparty default increases both the magnitude and the persistence of the efficiency loss on the dynamic transition path to a new steady state.

\section{Literature review}

Previous research has emphasized asymmetric information and market failure as causes of the financial crisis (Chiu and Koeppl [2011], Camargo and Lester [2011]). Dang et al. [2009, 2012], Gorton and Ordonez [2012], Farhi and Tirole [2012] and Hellwig and Zhang [2012] study the effect of endogenous information structure and market liquidity. This paper takes a different approach, exploring the possibility that there is a simpler explanation for the crisis - namely, an increase in collateral risk amplified through the mechanism of contagious counterparty default.

This approach is closely related to that of Kocherlakota [2001], in which collateral risk makes it harder for a lender to enforce payment of the promised share of a project. As in Kocherlakota [2001], it is too costly to collect the promised payment from borrowers, other than to seize the risky collateral. The difference is that, when the value of collateral drops, lenders are not able to withdraw funding from borrowers, even though only a tiny fraction of lenders observe the shock. The repayment of repo contracts is supported mostly by debt rollover. But equilibrium rollover will collapse when a small fraction of lenders want to withdraw, after observing the shock.

The term structure of repo borrowing in my model is exogenous. Brunnermeier and Oehmke [2013] shows that the exemption from automatic stay of short-term repo contracts triggers a matu- 
rity rat race, so, in equilibrium, banks borrow inefficiently short-term. But it would be interesting to endogenize the term structure in the future and study its effect, as in Williamson [2013].

The repo market in my model allows banks and investors to share profitable opportunities, as in Kiyotaki and Moore [2002] and Berentsen et al. [2007]. Many authors have used the workhorse model of Diamond and Dybvig [1983] to study traditional banking crises, but few have provided models of the repo market. Martin et al. [2011] focuses on the repo market between cash providers and financial intermediaries. I focus on repo lending between financial intermediaries to provide a complementary approach to understanding systemic risk. Gennaioli et al. [2013] presents another model of the shadow banking system, in the spirit of Diamond and Dybvig [1983]. In empirical work by Gorton and Metrick [2012a], the authors take the view that the recent crisis was a system-wide self-fulfilling bank run. While the Diamond-Dybvig model is important for understanding panics, it is unclear how it explains the 'runs' that occurred in the bilateral repo market. Collateral plays the same role in repo markets that deposit insurance plays in traditional banking and should have prevented a self-fulfilling bank run in a Diamond-Dybvig-style model. I focus, instead, on studying systemic risk and equilibrium dynamics in the repo market without runs.

This paper subscribes to the view, expressed in Sargent [2013], that liquidity problems are the result of market incompleteness, and, hence, the solution to a liquidity problem is model-dependent. I model the shadow banking sector with two questions from Moore [2011] in mind: Why do financial intermediaries hold mutual gross positions, and do these gross positions create systemic risk?

The paper is related to the study of banks' risk-taking behavior, as in Allen and Gale [2001]. In my paper, investment in a profitable long-term project is risky, as it is uncertain when the project will mature.

In my paper, a lender whose counterparty defaults is more likely to default when she invests in her long-term project. The financial contagion effect in the paper is in the spirit of Allen and Gale [2000]. Here, the effect takes place on the dynamic equilibrium path and has explicit implications for variables such as the haircut.

Liquidity hoarding that results from collateral risk is reminiscent of the precautionary demand for funding, as in Frenkel and Jovanovic [1980]. There is also a speculative motive for liquidity hoarding - to buy assets at fire sale prices in the future - as in Gale and Yorulmazer [2013]. Gale and Yorulmazer [2013] list two possible explanations for the phenomenon of liquidity hoarding: 
counterparty default risk and the fear that participation in lending may compromise a lender's future access to liquidity. Both ingredients contribute to the repo market freeze and to liquidity hoarding in my model.

The (endogenous) characterization of haircuts is related to the study of endogenous leverage initiated by Geanakoplos and Zame [1997] and developed by Fostel and Geanakoplos [2012]. Haircuts in these papers are pinned down by the price of Arrow securities, subject to additional constraints. In my model, the repo contract is the only contract traded in the market, and the haircut is determined by a necessary condition for equilibrium rollover. This complements the extensive literature on credit cycles, starting with Kiyotaki and Moore [1997a] and Bernanke and Gertler [1989], with recent development including Adrian and Shin [2010], Brunnermeier and Sannikov [2012] and Gertler and Kiyotaki [2013]. In all of these papers on credit cycles, the borrowing constraint is exogenous and always binding.

Another feature of the repo market is that investors can build leverage through rehypothecation (see Singh and Aitken [2010] for empirical evidence; see Bottazzi et al. [2012] for a theory of rehypothecation). Additional issues introduced to the repo market by rehypothecation, such as novation (see Duffie [2010]), is left for further research. Unsecured lending in a long-term relationship, as in Kehoe and Levine [1993], is not considered here.

Disruption in the repo market between money market mutual funds (MMMF) and brokerdealers also played a major role in the crisis. I abstract from these issues and focus instead on the repo market between dealer banks. Gorton and Metrick [2012b] show that during the financial crisis, MMMF did not reduce net lending to the repo market as a whole. The disruption in the repo market took place in the bilateral repo market between broker-dealers or hedge funds and broker-dealers. Unsecured lending though such markets as the Fed funds market is not allowed (see Afonso and Lagos [2012] for a model about the market). Operational risk such as settlement fails in the repo market (see Fleming and Garbade [2005]) is also not modeled.

The rest of the paper is organized as follows. Section 2 introduces in more detail institutional features that the model aims to capture and stylized facts of the crisis that motivate the exercise. Section 3 introduces the model. In section 4, I formally define the model's dynamic equilibrium. Section 5 discusses efficiency of the model. In section 6 , I characterize the equilibrium with rollover of the repo contract, study the efficiency gain of using repo contracts and characterize the efficiency 
loss from maturity mismatch and collateral risk. Section 7 studies the stability of the shadow banking system by looking at the transition dynamics triggered by a small but unexpected increase in collateral risk. Section 8 concludes the paper.

\section{Shadow banking and the repo market: institutional features and stylized facts}

In this section, I explain in more detail institutional features and stylized facts of collateral risk, the repo market, and the shadow banking system. ${ }^{7}$

Shadow banking and repo lending between financial intermediaries In many financial markets, either the demand side or the supply side involves mainly agents from the real sector, whereas in the repo market, many participants are financial intermediaries who could be on either side of the market. In particular, broker-dealers lend to each other in the repo market as part of the process of credit creation in the shadow banking system. Hedge funds and broker-dealers implement arbitrage strategies with each other using securities lending contracts. This trade reduces the cost of investment and arbitrage for the participants.

Credit creation in the shadow banking system typically starts with loan origination and loan warehousing and ends with wholesale funding provided by such institutions as MMMF. Before the loans reach the final cash suppliers, they need to be packaged into asset-backed securities (ABS), collateralized debt obligations (CDO) and asset-backed commercial paper (ABCP), which typically involves securities issuance, warehousing, tranching and intermediation. ${ }^{8}$ The intermediate stages take time and rely on financing through the interbank lending market. An intermediation chain comprised of broker-dealers and other intermediaries of the shadow banking system is formed during the process. This intermediation chain within the shadow banking system relies heavily on shortterm collateralized loans, such as repo. Repo financing in these intermediate steps is not directly financed by the final cash suppliers, but by other broker-dealers and financial intermediaries. This market-based intermediation is what distinguishes a shadow banking system from a traditional

\footnotetext{
${ }^{7}$ See, for example, Gorton and Metrick [2012a] and Copeland et al. [2012] for more details on the institutional features related to the repo market and the financial crisis.

${ }^{8}$ See Pozsar, Adrian, Ashcraft, and Boesky [2013].
} 
(commercial) banking system.

Maturity mismatch, solvency and liquidity of financial intermediaries Agents in the repo and securities-lending markets rely on short-term debt to finance investments of longer maturity. ${ }^{9}$ The maturity mismatch links the liquidity of the short-term lending market to borrowers' solvency. In the case of Lehman Brothers, the crisis started from the asset side rather than from short-term financing per se. The CDOs, - illiquid, long-term investments - that Lehman was initiating started losing money and became hard to sell long before the crisis. To wait for the investment to turn around, the bank had to roll over the debt. In the end, Lehman lost the race, ran out of collateral and was forced into bankruptcy. The bankruptcy was not necessarily a self-fulfilling run. According to a Wall Street Journal report: "Six weeks before it went bankrupt, Lehman Brothers Holdings Inc. was effectively out of securities that could be used as collateral to back the short-term loans it needed to survive." And Lehman had to rely on "Repo 105", a way to borrow against collateral without exposing its high leverage to the public, as early as the end of 2007. Even without a run, the bank may have had to default as it ran out of collateral. ${ }^{10}$

Speculation and arbitrage through securities lending also typically involve maturity mismatch. Convergence trades, which involve going long on one asset and short on a similar asset, typically involve maturity transformation, as a difference in liquidity is often associated with the spread between similar assets, and it takes time to realize the arbitrage profit. If it takes longer than expected to realize those gains from trade, the arbitrageurs may run out of funding and end up insolvent, as Lehman Brothers did. The downfall of Long-Term Capital Management ${ }^{11}$ and MF Global $^{12}$ are similar cases.

In all these cases, the solvency of a financial intermediary depends on the maturity of investment projects and the liquidity of the repo or securities lending market. The solvency and liquidity of a financial intermediary is best understood in terms of an equilibrium model.

\footnotetext{
${ }^{9}$ Adrian et al. [2009] shows that about $65 \%$ of outstanding repos of primary dealers are overnight repos.

10 "Repos Played a Key Role in Lehman's Demise", http://online.wsj.com/article/SB10001424052748703447104575118150651790066.html

${ }^{11}$ http://en.wikipedia.org/wiki/Long-Term_Capital_Management\#Downturn

${ }^{12}$ http://en.wikipedia.org/wiki/MF_Global
} 


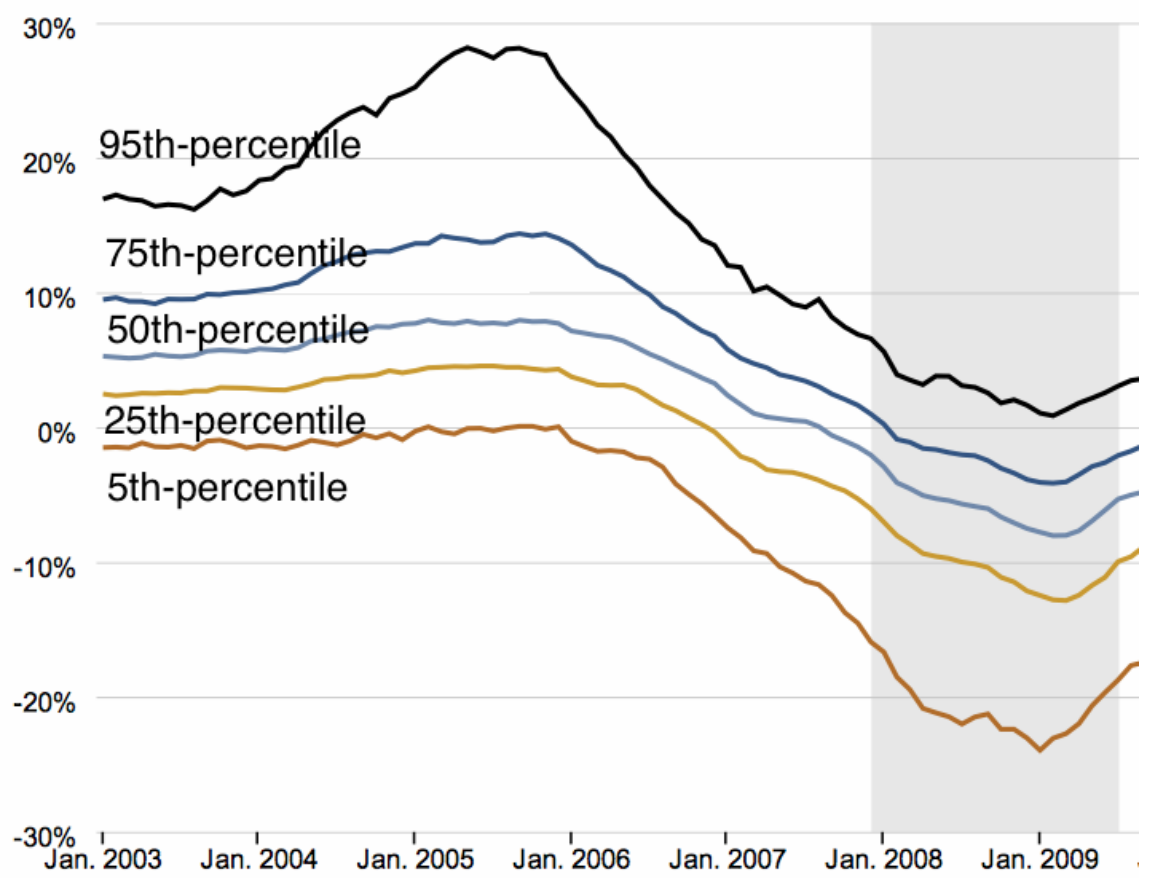

Figure 1: Distribution of home price changes by county (from NYFed website: http://www.newyorkfed.org/home-price-index/)

\section{Collateral risk in the 2007-2008 financial crisis}

According to the home-price-index of the New York Fed, ${ }^{13}$ the growth rate of housing prices slowed down before 2007 and turned negative close to the end of 2007. Figure 1 illustrates the year-overyear changes in housing prices in the US at the county level. In August 2007, 50\% of counties experienced negative price changes and at the end of 2007 , more than $75 \%$ of counties started to show a decline in housing prices. The grey area in the figure marks the great recession.

As housing prices spiraled downward, the riskiness of mortgage-backed securities (MBS) increased. Figure $2^{14}$ shows the market price index for a credit default swap contract that provided insurance against the default risk of a pool of mortgage-backed securities issued in early 2006. The discrepancy between the par value, 100, and the actual price index measures the shift in market beliefs about the riskiness of the mortgage-backed securities. The figure shows the index for tranches with a AAA rating to tranches with a BBB- rating. Before mid-2007, the market's belief about the

\footnotetext{
${ }^{13}$ http://www.newyorkfed.org/home-price-index/

${ }^{14}$ According to http://www.nera.com/nera-files/PUB_Subprime_Series_Part_IX_0412.pdf.
} 


\section{ABX.HE 06-01}

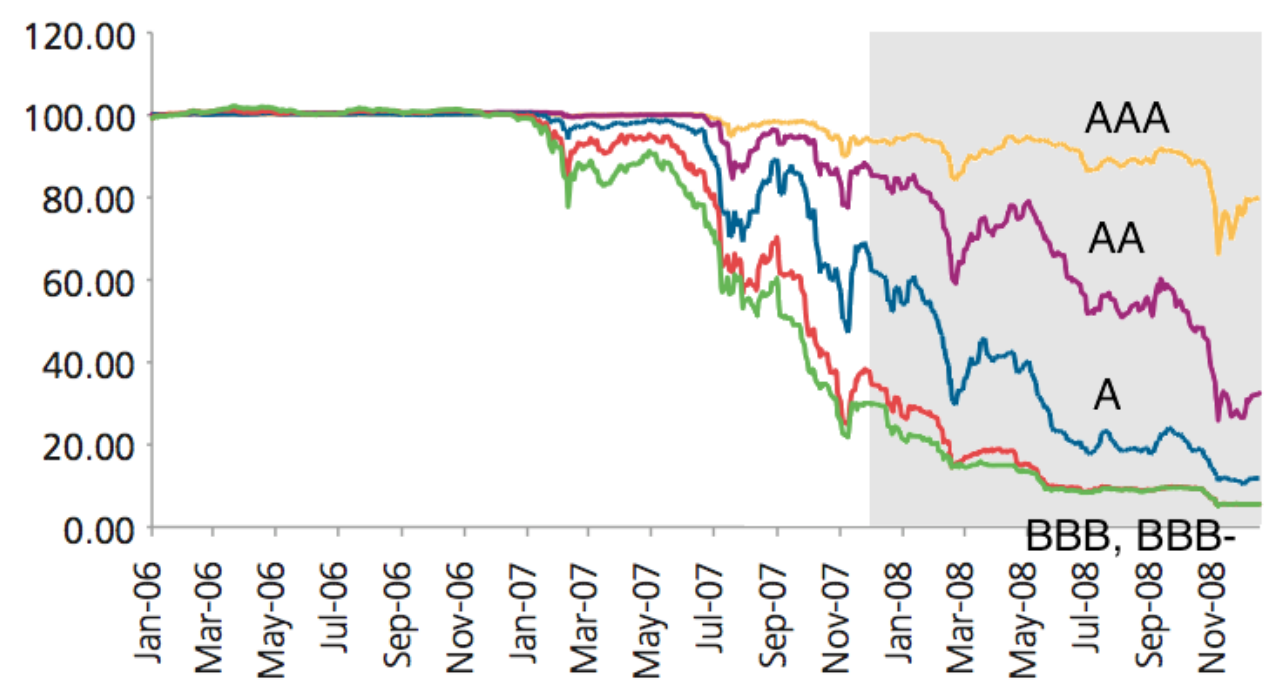

Figure 2: ABX index and risk of mortgage backed securities.

riskiness of all tranches barely moved. Riskiness of tranches with lower ratings increased first, at the beginning of 2007, and then in July 2007, riskiness of AAA tranches increased from zero to a positive number and kept increasing. The sudden changes in the price index imply that the shift in market beliefs came as an unexpected shock.

Why was there a sudden shift in the market belief about collateral risk? Dang et al. [2009, 2012 ] relate this to the information sensitivity of the debt contract and the lemons problem of MBS. However, the link between the changes in housing prices and the riskiness of mortgagebacked securities indicates that the risk is more likely to be related to the unexpected collapse of the housing market in the whole country, rather than to the lemons problem that arises from the quality deterioration of a fraction of mortgages. And the collapse of the housing market is so widely publicized that asymmetric information on this fact was unlikely. Thus in this paper, I take the view that the crisis was triggered by an unexpected increase in collateral risk, rather than by market failure due to a lemons problem.

Balance sheet adjustments of financial intermediaries and liquidity of the bilateral repo market He et al. [2010] estimates that, on the asset side, hedge funds and broker-dealers 
reduced holdings of securitized assets by approximately $\$ 800$ billion during the 2008 crisis. It was not just the size of broker-dealers' balance sheets that changed; the composition changed as well. Before the crisis, in November 2007, credit and mortgage-related assets made up of $32 \%$ of the total value of the trading assets of Goldman Sachs, Morgan Stanley and Merrill Lynch. After the crisis, in March 2009, they accounted for 23\%.15 The flight to such safe assets as treasury bills may be related to the increasing market risk of securities and is also consistent with their reduced activity in the repo market, where the haircut for risky collateral assets increased sharply. ${ }^{16}$ Gorton and Metrick [2012b] finds through Flow of Funds data that both the Repo assets and liability of broker-dealers shrank during the crisis, indicating the freeze of the repo market and broker-dealers' reduced activity in the market, as illustrated in Figure 3. This evidence implies that not only financial intermediaries' balance sheet, but also the portfolio composition of the balance sheet in the shadow banking system, may have contributed to and been affected by the financial crisis.

Krishnamurthy et al. [2012] shows that funding from cash providers such as MMMF did not change dramatically during the crisis. This implies that the dramatic change happened in the bilateral repo market between broker-dealers and hedge funds, which is where increasing haircut is reported in Gorton and Metrick [2012a,b] and Hördahl and King [2008]. This is consistent with Gorton and Metrick [2012b]'s finding that repo lending of investors other than money market mutual funds shrunk dramatically during the crisis. (See Figure 3 for dynamics in repo lending and borrowing. See Figure 4 for dynamics in haircut.)

\section{The model}

The model is set in continuous time. The economy starts at $t=0$ and lasts forever. There is a continuum of agents of constant measure. At any moment, there is a constant inflow of entrants, $\eta$, and an equal outflow of exits.

There is a durable consumption good in the economy and there are some productive trees. A

\footnotetext{
${ }^{15}$ See Table 7 of He et al. [2010]. The definition of a trading asset is "a collection of securities held by a firm that are held for the purpose of reselling for a profit. Trading assets are recorded as a separate account from the investment portfolio." (http://www.investopedia.com/terms/t/trading-assets.asp)

${ }^{16}$ For example, Gorton and Metrick [2012a] documents the devaluation of BBB asset-backed securities and a sharp increase in haircut in the bilateral repo market during the crisis.
} 


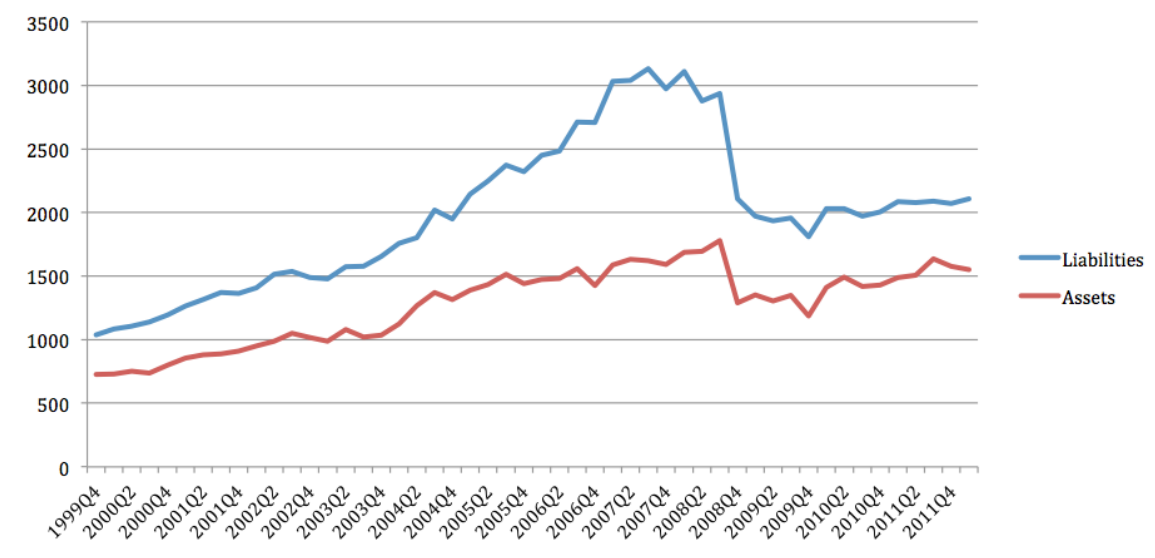

Broker-dealers' repo assets and liabilities, in \$billions

Figure 3: The freeze of the repo market. (from Gorton and Metrick [2012b])

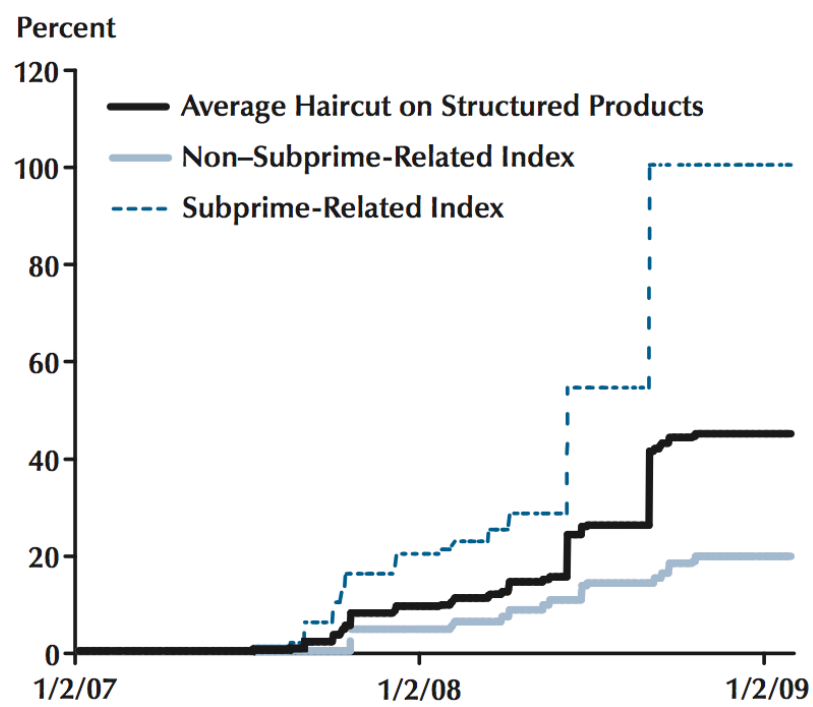

Figure 4: Collateral quality and haircut dynamics during the crisis. (from Gorton and Metrick [2009]) 
tree bears consumption goods only at its maturity date. The maturity date of a tree is random and follows an idiosyncratic Poisson process.

Agents are ex ante homogeneous. They are endowed with $a_{0} \in \mathbb{R}_{++}$units of collateral trees and $m_{0} \in \mathbb{R}_{++}$units of consumption good when they enter the economy.

An agent's expected payoff at time $t$ is $\mathbb{E}_{t} \int_{t}^{T} c_{u} e^{-\rho(u-t)} d u$, where $c_{u} d u$ is the measure of apples she consumes between $u$ and $u+d u, \rho$ is the discount factor and $T$ is the random moment when she leaves the economy.

A collateral tree matures with Poisson rate $\mu \in \mathbb{R}_{++}$. If a collateral tree matures at date $t$, it bears $y \cdot \omega_{t}$ apples at maturity date $t$, with $y \in \mathbb{R}_{++} \cdot \omega_{t}$ is the aggregate state of the economy at date $t$; it represents the aggregate risk that the quality of a collateral asset may deteriorate, or the aggregate collateral risk. There are two aggregate states, $\omega_{t} \in\{0,1\}$. When $\omega_{t}=1$, every tree bears $y$ apples if it matures at $t$, and when $\omega_{t}=0$, every tree bears no apples. I assume that the economy is in the good state initially, $\omega_{0}=1$. And the bad state, $\omega=0$, is assumed to be an absorbing state. The arrival of the bad state follows a Poisson process with rate $\chi \in \mathbb{R}_{++}$. As the likelihood of shock, $\omega_{t}=0$, can be small or large, the model applies to collateral assets of both high and low quality.

Another type of tree in the economy represents investment opportunities. An investment opportunity is a long-term technology that transforms consumption goods at the investment date into consumption goods at the (random) maturity date. The maturity date arrives with Poisson rate $\pi \in \mathbb{R}_{++}$. The investment is one-shot and doesn't require additional resources at subsequent dates. If an agent does not exploit the investment opportunity the moment it arrives, she loses it. With $i$ units of consumption good as input at the investment date, the output at maturity is $\frac{\rho+\pi}{\pi} f(i)$, where $f: \mathbb{R}_{++} \rightarrow \mathbb{R}_{++}$. In the benchmark model, I assume that the production function takes the form, $f(i)=\theta i^{\alpha}$, with productivity parameter $\theta \in \mathbb{R}_{++}$and $\alpha \in(0,1)$, so $f(i)$ is concave and the marginal output at zero input is infinity. I assume that only the agent who invests in a long-term technology has the skill to manage it. The output from the technology if other agents own the project is zero, and other agents cannot take the output from it away from the investor.

The long-term investment opportunity is endowed to agents with delay, which represents the search friction to find a profitable investment opportunity. After entering the economy, each agent receives at most one investment opportunity, at a random date. The arrival date of an agent's 


\section{withdraw storage, LT investment}

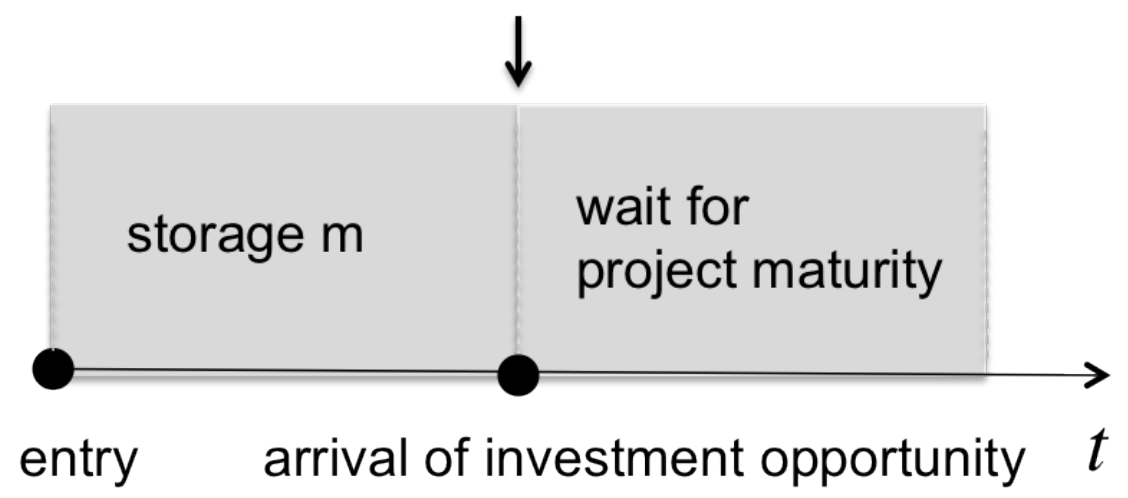

Figure 5: The life cycle of an agent in Autarky.

investment opportunity follows an idiosyncratic Poisson process, arrival rate $\lambda \in \mathbb{R}_{++}$.

An agent leaves the market after her collateral asset and the long-term project mature. I assume for simplicity that agents lose their chance to find an investment opportunity after their collateral matures.

Figure 5 describes a realization of the life cycle of an agent in Autarky. Upon entry, the agent decides her consumption and storage. She stores some of the consumption good in order to provide for investment in the long-term technology. When the investment opportunity arrives, she draws her consumption good from storage to invest in the project and then waits for the project to mature. She leaves the market after both her asset and the project mature.

Since storing consumption is not productive and delays consumption, a financial system can improve efficiency by allocating consumption goods in storage to agents who need more funding to take advantage of the investment opportunity.

The repo market allows agents waiting for long-term projects to earn interest by lending, and agents with long-term projects can increase their investment by borrowing against their collateral. The repo market is assumed to be perfectly competitive. A repo contract has three components: the interest rate $R_{t} \in \mathbb{R}_{+}$, haircut $h_{t} \in[0, \infty)$ and maturity $d t$. According to the contract, a borrower puts down $h_{t}$ units of collateral for each unit of consumption she borrows from the lender at the moment of signing the contract. At maturity, date $t+d t$, if no party defaults on the contract, 
then the borrower pays $1+R_{t} d t$ units of consumption good for each unit she borrows at $t$, and the lender delivers $h_{t}$ units of collateral asset back to the borrower for each unit of borrowing. ${ }^{17}$ Given the contract, an agent with asset holding $a$ can borrow up to $\frac{a}{h_{t}}$.

At the maturity date of a repo contract, the borrower can choose to default or repay the debt. There are two ways to repay the debt: by using consumption goods that the borrower stored from her endowment or that she obtained when her tree matures; or by borrowing from other lenders. This is what I refer to as repo rollover. As long as a borrower has not borrowed up to $\frac{a}{h_{t}}$, she can choose to roll over her debt.

For lenders, as in Acharya and Bisin [2013], I assume that the repo market is an opaque, overthe-counter market, so the repo contract is not conditional on information such as the borrowers' balance sheet. ${ }^{18}$ At any moment, one repo contract clears the whole market. I assume that every lender is assigned to one borrower in the market-clearing process. ${ }^{19}$ After the repo market clears, lenders meet their counterparty. At that moment, lenders can see borrowers' information and whether or not they will default. Then, lenders can decide whether to carry out the repo contract or to reject the borrower and wait until next period.

Since a lender is matched with one borrower, the counterparty risk, the risk that a borrower may default, is undiversified. Denote the probability that the counterparty defaults on a repo contract signed at $t$ as $\delta_{t} d t$. Counterparty default is a shock to the lender's portfolio. For a lender with $a$ units of asset and $s$ units of apple in repo account, she will hold $a+h_{t} s$ units of asset but will have no funding left in the repo account when default happens. If default happens with probability one, the contract is observationally equivalent to a spot transaction in which the borrower sells the asset to the lender, at unit price $\frac{1}{h_{t}}$.

To simplify the analysis, I impose the following restrictions on agents' strategies. A borrower is not allowed to borrow or lend in the repo market after she defaults. A lender is not allowed to move additional funding from storage to the repo market after she loses all her funding to the

\footnotetext{
${ }^{17}$ Default does not incur any loss to the defaulting agent other than the collateral asset in the repo contract. For example, for an agent with a long-term investment, default does not affect her return from the investment because the investment generates only private return for the borrower that no one else can control.

${ }^{18}$ Trading delay due to search friction, as inDuffie et al. [2005], Lagos and Rocheteau [2009], Afonso and Lagos [2012], is also ignored here.

${ }^{19} \mathrm{~A}$ lender can only lend to one borrower, a borrower can borrow from several lenders.
} 
repo market when she meets a defaulting borrower or she herself defaults on a repo contract. ${ }^{20}$ With these two simplifications, we focus on the borrowing decision of agents who need to finance their long-term investment and lending decisions of those lenders who have not met a defaulting borrower. Additionally, I assume that interest payments from repo lending must be consumed and cannot be accumulated for repo lending or storage.

\subsection{Discussion}

If all borrowers default with probability one, the market is equivalent to a market for trading the asset; however, agents cannot choose to buy or sell the asset and lend or borrow against the asset. What is missing is an additional market for a firesale asset. In such a case, lenders do not worry about counterparty default risk, and buyers of the asset can optimize their portfolio based on their risk exposure. While the current setup is in line with the observation that the repo market is much more liquid than the market for trading assets, I will study the effect of introducing an additional market in the extension.

I also assume that the default over the collateral does not affect agents' payoff from their project investment. Default does not lead to bankruptcy, and collateral delivery is the only requirement if a borrower defaults. The separation of default from bankruptcy allows the agent to buy and sell the collateral asset through repo contracts (and default). And this is consistent with the exemption of repo contracts from "automatic stay" (Garbade [2006]). The separation also allows the model to characterize credit derivative markets. I also assume that default does not incur loss to the borrower other than the collateral she puts down because other investors cannot separate he from her long-term investment. This is consistent with moral-hazard frictions that lenders may face.

Another property of the repo contract is that dividends from the collateral asset before the maturity of the repo contract belong to the lender. This is not an issue for overnight repo, as no dividend is generated from an asset overnight. Likewise, since the maturity of a repo contract is assumed to be infinitesimal in my model, there will not be any dividend payment from the asset before the maturity of the contract.

I assume that lenders face undiversified counterparty risk. Although banks in the real world

\footnotetext{
${ }^{20}$ When losing her funding of amount $s$ to the repo market, she has $s(1+h)$ additional collateral asset. But she can still borrow from the repo market.
} 
are large enough to diversify the idiosyncratic coutnerpary risk in normal times, diversification would be impossible when default is triggered by certain aggregate shocks. My assumption will be more useful when studying the dynamic response of the financial system to aggregate shocks. Another reason I make this assumption is that I am modeling the repo market between financial intermediaries. As financial intermediaries borrow and lend on a large scale and the total number of financial intermediaries is limited, undiversified counterparty risk is more relevant for the inter-bank repo market.

\section{Equilibrium definition}

In this section, I give the formal definition of the dynamic equilibrium with a certain initial distribution of agents and initial aggregate state. In the equilibrium definition subsection, I first formalize the individual agent's problem, after which I define the law of motion of the economy. And in the end, I define the equilibrium.

\subsection{An agent's problem}

An agent's problem depends on whether or not the repo market functions, which, in turn, depends on the aggregate state.

When $\omega_{t}=0$, the repo market is not functioning, as the supply of valuable collateral asset in this state is 0 .

When $\omega_{t}=1$, the repo market is functioning. Then, an agent's problem depends on her portfolio, her lending/borrowing history and whether she is still looking for an investment opportunity or she has already invested in a project. In that case, the life cycle of an agent who manages to find a long-term project is illustrated in Figure 6. After entry, the agent allocates her consumption good endowment to consumption, storage and repo lending. Before she finds her long-term technology, she continues making decisions on consumption, storage and repo lending. ${ }^{21}$ When she finds her long-term project, she withdraws consumption goods from storage and repo lending, borrows from the repo market and invests in the long-term project. Before her long-term investment matures, she does not have consumption goods left so she decides whether to roll over her debt or default. If

\footnotetext{
${ }^{21}$ When lending to other agents, the agent may meet a default borrower with Poisson rate $\delta$. If that happens, her lending turns into additional asset holdings and she loses her capacity to continue lending.
} 


\section{withdraw storage, withdraw lending, borrow, LT investment}

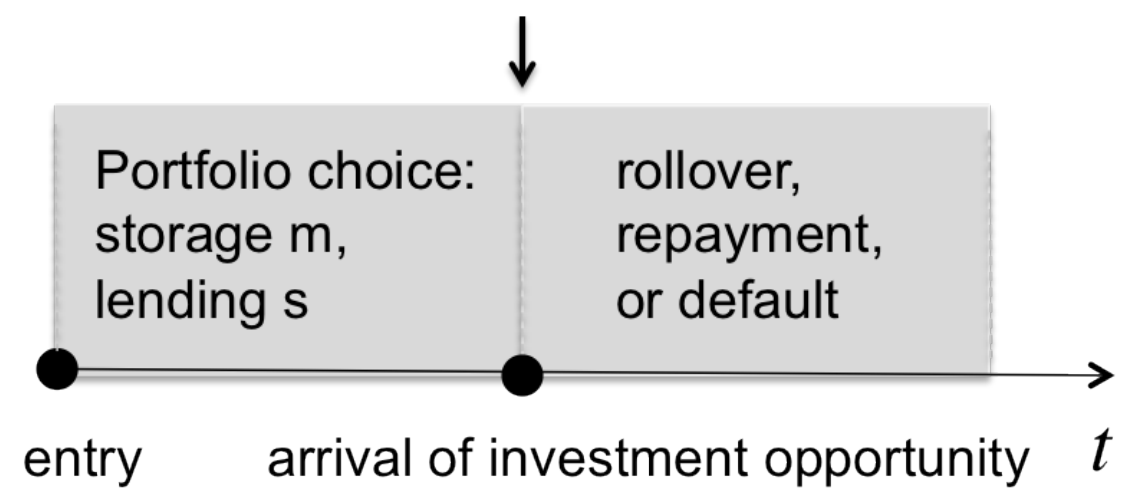

Figure 6: life cycle of an agent with access to the repo market

her long-term investment or asset matures when she is still rolling over her borrowing, she repays her outstanding debt, consumes the remaining consumption and waits for the rest of her trees to mature. After all her asset matures and she consumes all the consumption she owns, she leaves the market.

To solve an agent's problem when $\omega_{t}=1$, I go backward. I first solve her problem after project investment; then, I solve her problem at long-term investment, her problem before the investment, and, finally, her problem at the beginning of her life. I then explain an investor's problem when $\omega_{t}=0$. Table 1 summarizes the value function and policy functions for an agent's problem when she faces different situations. I now explain an agent's problem in different situations.

Situation 1: $\omega_{t}=1$, agent's problem after LT investment

$$
\begin{aligned}
W_{t}(a, m, s, i)=\max _{c, m^{\prime}, s^{\prime}} c+E & W_{t}\left(a, m^{\prime}, s^{\prime}, i\right), \\
c+m^{\prime}+s^{\prime} & \leq s+m, \\
\text { s.t. } \quad & \geq-\frac{a}{h_{t}}, \\
c, m^{\prime} & \geq 0,
\end{aligned}
$$

where the first constraint is the agent's budget constraint; the second is the collateral constraint, 


\begin{tabular}{|c|c|c|c|}
\hline situation & value function & policy function & distribution \\
\hline$\omega_{t}=1$, after LT investment & $W_{t}(a, m, s, i)$ & $\begin{array}{l}\text { consumption } \tilde{c}_{1 t} \\
\text { storage } \tilde{m}_{1 t} \\
\text { net lending } \tilde{s}_{1 t} \\
\text { acceptance } \tilde{z}_{1 t} \text {, } \\
\text { default } \tilde{d}_{1 t}\end{array}$ & $F_{1 t}(a, m, s, i)$ \\
\hline$\omega_{t}=1$, at $\mathrm{LT}$ investment & $U_{t}(a, m, s)$ & $\begin{array}{l}\text { consumption } \tilde{c}_{I t} \\
\text { storage } \tilde{m}_{I t} \\
\text { net lending } \tilde{s}_{I t} \\
\text { investment } \tilde{i}_{I t}\end{array}$ & 0 \\
\hline$\omega_{t}=1$, active before LT investment & $V_{t}(a, m, s)$ & $\begin{array}{l}\text { consumption } \tilde{c}_{0 t} \\
\text { storage } \tilde{m}_{0 t} \\
\text { net lending } \tilde{s}_{0 t} \\
\text { acceptance } \tilde{z}_{0 t} \\
\text { default } \tilde{d}_{0 t}\end{array}$ & $F_{0 t}(a, m, s)$ \\
\hline$\omega_{t}=1$, deactivated before LT investment & $V_{t}^{d}(a, m)$ & $\begin{array}{l}\text { consumption } \tilde{c}_{d t} \\
\text { storage } \tilde{m}_{d t}\end{array}$ & $F_{d t}(a, m)$ \\
\hline$\omega_{t}=0$, before LT investment & $V_{t}^{A}(a, m)$ & $\begin{array}{l}\text { consumption } \tilde{c}_{A} \\
\text { storage } \tilde{m}_{A}\end{array}$ & $G_{0 t}(a, m)$ \\
\hline
\end{tabular}

Table 1: Value functions and policy functions 
which imposes that borrowing cannot exceed $\frac{a^{s}}{1+h}$; and the last two are non-negativity constraints for consumption and storage allocation. Agents choose consumption $c$, storage $m^{\prime}$ and repo lending $s^{\prime}$ to maximize the payoff from consumption and continuation value $E W_{t}\left(a, m^{\prime}, s^{\prime}, i\right)$, which depends on random events between $t$ and $t+d t$.

$$
\begin{aligned}
& E W_{t}(a, m, s, i) \\
= & \mu d t[a+m+s+f(i)]+\pi d t\left[\frac{\mu}{\rho+\mu+\chi} a+m+s+\frac{\rho+\pi}{\pi} f(i)\right]+\chi d t[m+f(i)] \\
+ & \delta_{t} d t \mathbb{I}_{s>0} e^{-\rho d t} \max _{z \in[0,1]}\left[z W_{t+d t}\left(a+h_{t} s, m, 0, i\right)+(1-z) W_{t+d t}(a, m+s, 0, i)\right] \\
+ & \left(1-\left(\mu+\pi+\chi+\delta_{t} d t \mathbb{I}_{s>0}\right) d t\right) e^{-\rho d t} \max _{d \in[0,1]}\left[d\left(\frac{\mu y}{\rho+\mu+\chi}\left(a+h_{t} s\right)+m+f(i)\right)\right. \\
+ & \left.(1-d)\left(R_{t} d t s+W_{t+d t}(a, m, s, i)\right) \mathbb{I}_{s>0}+(1-d) W_{t+d t}\left(a, m,\left(1+R_{t} d t\right) s, i\right) \mathbb{I}_{s \leq 0}\right] .
\end{aligned}
$$

The continuation value depends on several random events. With probability $\mu d t$, the agent's asset matures. In this case, she repays $-s$ apples to her lenders, if $s<0$, or withdraws $s$ apples from inter-bank lending, consumes $a+m+s$ apples, and waits for her long-term project to mature, which delivers expected payoff $f(i)$. With probability $\pi d t$, the agent's long-term investment matures. In this case, she repays her debt or draws lending from the repo market, consumes $m+s+\frac{\rho+\pi}{\pi} f(i)$ apples, and waits for her collateral asset holdings to mature, which delivers expected payoff $\frac{\mu}{\rho+\mu+\chi} a$. With probability $\chi d t$, the aggregate devaluation shock hits the economy and the collateral asset becomes worthless. So if $s<0$, she default on her debt, consumes $m$ apples that she withdraws from her storage account and waits from her long-term investment to mature. If $s>0$, on seeing the aggregate shock hitting the economy, she withdraws her apples from the repo market and consumes the $s$ apples immediately. The next term is the expected payoff from the event that the counterparty defaults. This term shows up only if the agent is lending in the repo market. So, if $s>0$, then with probability $\delta_{t} d t$, the agent meets a defaulting borrower. In this case, her payoff depends on whether she is willing to lend to the borrower after knowing that the borrowing is going to default. If she decides to lend to the defaulting borrower, her loan $s$ will turn into $h_{t} s$ units of additional asset holdings when the repo contract matures in $d t$ period. Thus, her continuation value with this choice is $e^{-\rho d t} W\left(a+h_{t} s, m, 0, i\right)$. If she decides not to lend to the defaulting borrower, she adds $s$ additional apples to storage account for $d t$ period. So her continuation value with this choice is $e^{-\rho d t} W(a, m+s, 0, i)$. With the residual probability, $\left[1-\left(\mu+\pi+\chi+\delta_{t} d t \mathbb{I}_{s>0}\right) d t\right]$, the 
agent meets a non-defaulting borrower and decides whether or not to default. If she defaults, her continuation value is $e^{-\rho d t}\left[\frac{\mu y\left(a+h_{t} s\right)}{\rho+\mu+\chi}+m+f(i)\right]$, where the first component is the expected payoff from the asset holdings, $m$ is the payoff from the consumption of apples withdrawn from the storage account and $f(i)$ is the expected payoff from the long-term investment. If she does not default, she will get $R_{t} d t s$ apples as interest payment, so her continuation value is $e^{-\rho d t} W\left(a, m,\left(1+R_{t} d t\right) s, i\right)$. Refraining from lending is ruled out here as long as interest rate $R_{t}$ is positive. If $s<0$, she needs to borrow from the repo market. Similarly, $e^{-\rho d t}\left\{\frac{\mu y\left[a+h_{t} s\right]}{\rho+\mu+\chi}+m+f(i)\right\}$ is her payoff from default, and $e^{-\rho d t} W\left(a, m,\left(1+R_{t} d t\right) s, i\right)$ is her payoff from rolling over her debt.

Debt rollover is an option only if $\left(1+R_{t} d t\right) s \geq-\frac{a}{h_{t}}$. So, if the state variable $s=-\frac{a}{h_{t}}$, the agent's borrowing constraint is already binding, so she must default. Thus,

$$
E W_{t}\left(a, m,-\frac{a}{h_{t}}, i\right)=m+f(i)
$$

which is equal to $m+f(i)$ plus some term of the same order of magnitude as the infinitesimal period $d t$.

Situation 2: $\omega_{t}=1$, agent's problem at long-term investment

$$
\begin{aligned}
& U_{t}(a, m, s)=\max _{c, m^{\prime}, s^{\prime}, i} c+W_{t}\left(a, m^{\prime}, s^{\prime}, i\right) \\
& c+s^{\prime}+m^{\prime}+i \leq s+m, \\
& \text { s.t. } \quad s^{\prime} \geq-\frac{a}{h_{t}} \text {, } \\
& c, m^{\prime}, i \geq 0 \text {, }
\end{aligned}
$$

where agents choose consumption, $c$, storage, $m^{\prime}$, lending or borrowing through the repo market, $s^{\prime}$, and investment in the long-term project, $i$, to maximize their payoff from consumption and continuation value $W_{t}\left(a, m^{\prime}, s^{\prime}, i\right)$. The constraints the agent faces are resource constraint, borrowing constraint and non-negativity constraints of the choice variables, $c, m^{\prime}$ and $i$. 
Situation 3: $\omega_{t}=1$, agent's problem before long-term investment

$$
\begin{aligned}
V_{t}(a, m, s)=\max _{c, s^{\prime}, m^{\prime}, z, d} c+E V_{t}\left(a, m^{\prime}, s^{\prime}\right), \\
c+s^{\prime}+m^{\prime} \leq s+m, \\
\text { s.t. } \quad \geq-\frac{a}{h_{t}}, \\
c, m^{\prime} \geq 0,
\end{aligned}
$$

which is similar to agents' problem after project investment, equation 1.

$$
\begin{aligned}
& E V_{t}(a, m, s) \\
= & \mu d t(a+m+s)+\lambda d t U_{t}(a, m, s)+\chi d t V_{t}^{A}(m) \\
+ & \delta_{t} \mathbb{I}_{s>0} d t e^{-\rho d t} \max _{z \in[0,1]}\left[z V_{t+d t}^{d}\left(a+h_{t} s, m\right)+(1-z) V_{t+d t}(a, m, s)\right] \\
+ & {\left[1-\left(\mu+\lambda+\chi+\delta_{t} \mathbb{I}_{s>0}\right) d t\right] \max _{d \in[0,1]} e^{-\rho d t}\left[d V_{t+d t}\left(a+h_{t} s, m, 0\right)\right.} \\
+ & \left.(1-d)\left(R_{t} d t s+V_{t+d t}(a, m, s)\right) \mathbb{I}_{s>0}+(1-d) V_{t+d t}\left(a, m,\left(1+R_{t} d t\right) s\right) \mathbb{I}_{s \leq 0}\right] .
\end{aligned}
$$

The continuation value has a similar expression to the continuation value 2 . The additional random event is the event of finding a long-term project. With probability $\lambda d t$, the agent finds a longterm project in $d t$ period. The continuation value contingent on the event is $U_{t}(a, m, s)$. With probability $\mu d t$, the agent's asset matures. ${ }^{22}$ And if a lender lends to a defaulting borrower, she will be deactivated, with continuation value, $V_{t+d t}^{d}\left(a+h_{t} s, m\right)$.

If $s=-\frac{a}{h_{t}}$, the agent's borrowing constraint is already binding, then she must default. So,

$$
E V_{t}\left(a, m,-\frac{a}{h_{t}}\right)=V_{t}^{A}(m)
$$

After default, the agent has no asset left. So her continuation value is the same as what she would have been under Autarky with storage $m$.

The problem of an agent deactivated because of lending to a defaulting borrower is

\footnotetext{
${ }^{22}$ The collateral asset of an agent is assumed to mature at the same time. This is not exactly consistent with the assumption that the maturity of collateral asset is idiosyncratic across agents because the asset an agent receives from other agents is assumed to mature at the same time as his own asset.
} 


$$
\begin{aligned}
V_{t}^{d}(a, m)=\max _{c, m^{\prime}} c+E V_{t}^{d}\left(a, m^{\prime}\right) \\
\text { s.t. } \quad c+m^{\prime} \leq m, \\
\quad c, m^{\prime} \geq 0
\end{aligned}
$$

where the continuation value is,

$$
E V_{t}^{d}(a, m)=\mu d t(a+m)+\lambda d t U_{t}(a, m, 0)+\chi d t V_{t}^{A}(m)+[1-(\mu+\lambda+\chi) d t] e^{-\rho d t} V_{t}^{d}(a, m) .
$$

The agent finds her long-term project with probability $\lambda d t$ and her continuation value is $U_{t}(a, m, 0)$.

\section{Situation 4: $\omega_{t}=0$}

The value function, $V_{A}(m)$ and policy functions, $\tilde{c}_{A}(m), \tilde{m}_{A}(m)$, solve the problem of an agent's problem before she finds her long-term projects.

$$
\begin{gathered}
V_{A}(m)=\max _{c, m^{\prime}} c+E V_{A}\left(m^{\prime}\right), \\
\text { s.t. } \quad c+m^{\prime} \leq m \\
\quad c, m^{\prime} \geq 0
\end{gathered}
$$

where the agents choose consumption $c$ and storage for the next period $m^{\prime}$ to maximize their payoff from consumption and continuation value $E \tilde{V}_{A}\left(m^{\prime}\right)$, subject to the resource constraint and nonnegativity constraints on consumption and storage. The continuation value depends on the random events that may happen during $d t$ period.

$$
E V_{A}(m)=\lambda d t \max _{0 \leq i \leq m}\{m-i+f(i)\}+\mu d t m+[1-(\lambda+\mu) d t] e^{-\rho d t} V^{A}(m) .
$$

With probability $\lambda d t$, the agent finds her long-term investment and, in that case, chooses optimally to invest in the long-term project and consumption so as to maximize her expected payoff $c+f(i)$, where $c=m-i$, subject to non-negativity constraints of consumption and investment. With probability $\mu d t$, her collateral asset matures and bears no apples at maturity and she loses her chance to find a long-term investment opportunity in the future. In that case, she consumes away the apples in the storage account and leaves the market. With the residual probability $1-(\lambda+\mu) d t$, nothing happens during the $d t$ period so her continuation value is $e^{-\rho d t} V^{A}(m)$. 


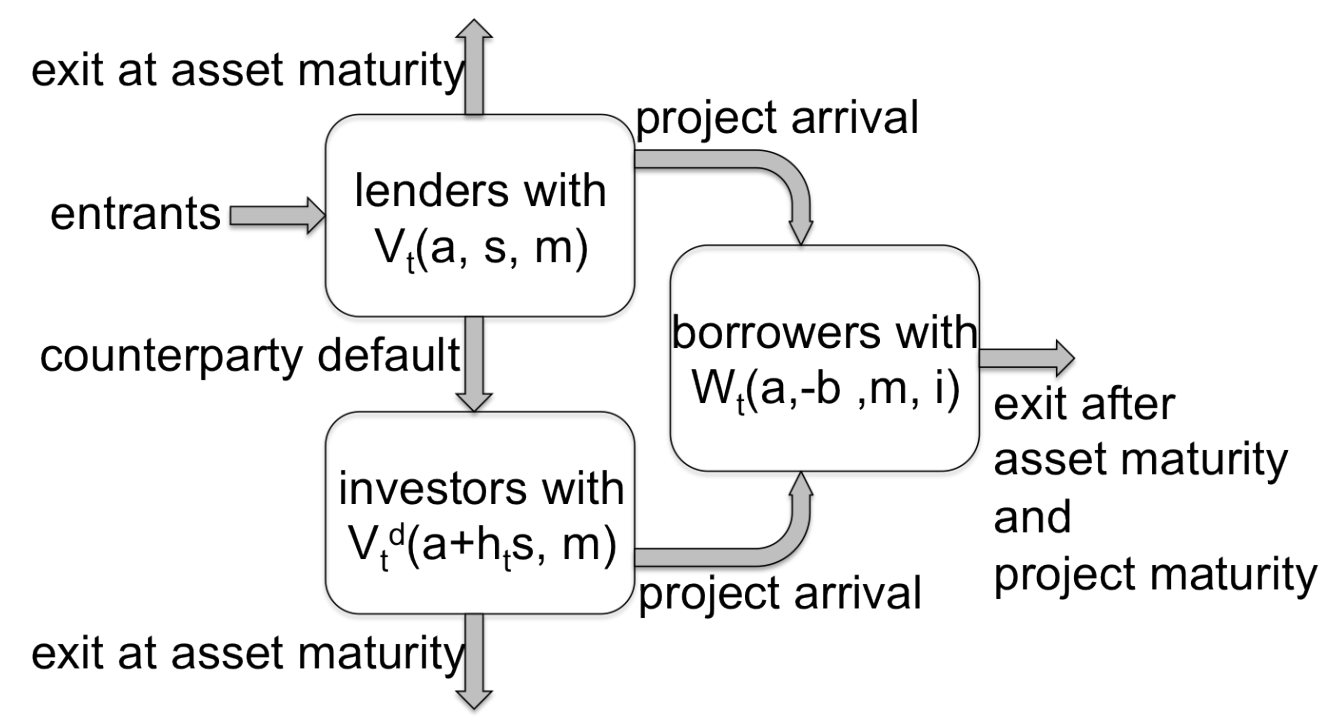

Figure 7: Law of motion of an agent's state before the realization of collateral shock $\left(\omega_{t}=1\right)$.

\section{Laws of motion for the distribution of agents}

The exact law of motion is left to the Appendix. Here, I illustrate the laws of motion on the equilibrium path, where $\omega_{t}=1, \forall t$ using Figure 7. All new entrants enter as active lenders and are counted in the distribution $F_{0 t}$. A lender leaves the pool of active lenders in three situations. If her collateral asset matures before she finds her long-term project, she leaves the economy after consuming all her consumption goods. If she meets a defaulting borrower, she enters the pool of deactivated lenders with distribution $F_{d t}$. If she finds her investment opportunity, she enters the pool of borrowers with distribution $F_{1 t}$. An agent in the pool of deactivated lenders leaves the economy if her collateral asset matures before she finds a project, or she enters the pool of borrowers when she finds her long-term project. An agent in the pool of borrowers exits the economy after both her project and collateral asset mature. She will stop borrowing when her collateral asset or project matures, or when she defaults on her loan.

\section{Equilibrium definition}

Definition 4.1. An equilibrium with initial distribution $F_{10}, F_{d 0}$ and $F_{00}$ and initial state $\omega_{0}=1$, is the repo contract term $\left\{R_{t}, h_{t}\right\}_{t \geq 0}$, default rate, $\left\{\delta_{t}\right\}_{t \geq 0}$, agents' policy functions and value functions and aggregate law of motion such that, 
(i) given $R, h$ and $\lambda$, agents' policy functions and value function solve their problems if $\omega_{t}=1$.

(ii) agents' policy functions and value functions solve their problem if $\omega_{t}=0$.

(iii) the contract $(R, h)$ clears the repo market given the distribution of agents and agents' decision function,

$$
\int \tilde{s}_{1 t}(a, m, s, i) d F_{1 t}(a, m, s, i)+\int \tilde{s}_{0 t}(a, m, s) d F_{0 t}(a, m, s)=0, \text { if } \omega_{t}=1, \forall t .
$$

(iv) the distribution of agents is endogenously determined by laws of motion.

(v) agents' expectation on default rate $\delta_{t}$ is consistent with the actual default rate,

$\delta_{t} d t=\frac{\int_{\{(a, m, s): s \leq 0\}} \tilde{d}_{1 t}(a, m, s, i) s d F_{1 t}^{1}(a, m, s, i)+\int_{\{(a, m, s): s \leq 0\}} \tilde{d}_{0 t}(a, m, s) s d F_{0 t}^{1}(a, m, s)}{\int_{\{(a, m, s): s \leq 0\}} s d F_{1 t}^{1}(a, m, s, i)+\int_{\{(a, m, s): s \leq 0\}} s d F_{0 t}^{1}(a, m, s)}$, for $\omega_{t}=1$.

$\delta_{t} d t$ is the probability that a lender's counterparty may default on her borrowing. Since the lender is ignorant of the borrower's portfolio, the lender's counterparty can be thought of as a random draw from the pool of borrowers, weighted by borrowers' funding demand. Suppose that an agent borrows to invest in a long-term project, and she also has invested all her apples in storage and in interbank lending. When the initial borrowing matures in $d t$ period, the cumulative probability that her project or collateral asset matures is $(\pi+\mu) d t$, which is negligible. She has two choices, to roll over her debt or to default. If every borrower chooses to default immediately after initial borrowing, $\delta_{t} d t=1$. $\delta_{t} d t<1$ when some agents choose to rollover their debt in equilibrium.

Definition 4.2. A stationary equilibrium with initial state $\omega_{0}=1$ is an equilibrium with initial distributions $F_{10}, F_{d 0}$ and $F_{00}$ and initial state $\omega_{0}=1$, such that $F_{0 t}(a, m, s)=F_{00}(a, m, s)$, $F_{d t}(a, m)=F_{d 0}(a, m)$, and $F_{1 t}(a, m, s, i)=F_{10}(a, m, s, i), \forall t$.

\section{$5 \quad$ Efficiency}

To understand the welfare loss from the market incompleteness, I study properties of efficient allocation in this section.

The social planner's choice is aggregate consumption flow, $C_{\tau}$, for each newly born agent at moment $\tau$, aggregate storage, $m_{\tau}$, and investment in long-term tech, $i_{\tau}$, for each agent with an opportunity to invest in the long-term technology.

The social planner's problem at moment $t$ is 


$$
\begin{aligned}
& \qquad \begin{aligned}
& S_{t}=\max _{\left\{C_{\tau}, m_{\tau}, i_{\tau}\right\}_{\forall \tau \geq t}} \int_{t}^{\infty} C_{\tau} e^{-\rho(\tau-t)} d \tau \\
& \qquad \begin{aligned}
C_{\tau} d \tau+(\lambda d \tau) \frac{\eta}{\mu+\lambda} i_{\tau}+m_{\tau} & \leq \int_{-\infty}^{\tau} \frac{\rho+\pi}{\pi} \theta i_{s}^{\alpha}(\pi d \tau) e^{-\pi(\tau-s)} \lambda \frac{\eta}{\mu+\lambda} d s \\
& +\int_{-\infty}^{\tau} a y \omega_{\tau}(\mu d \tau) e^{-\mu(\tau-s)} \eta d s+(\eta d \tau) M_{\tau}+m_{\tau-d \tau}
\end{aligned} \\
& \text { s.t. } C_{\tau}, m_{\tau}, i_{\tau} \geq 0 .
\end{aligned}
\end{aligned}
$$

In the objective function of the planner, $\eta d t$ is the measure of agents born during $\tau$ and $\tau+$ $d t$, and $e^{-\rho(\tau-t)}$ is the discount factor for future welfare gain. The planner chooses allocation, $\left\{C_{\tau}, m_{\tau}, i_{\tau}\right\}_{\forall \tau \geq t}$, to maximize the objective function, subject to nonnegative constraints of the choice variables and the resource constraint. The right-hand side of the resource constraint includes apples from maturing long-term projects from past investments, maturing collateral from agents born before $\tau$, and production from short-term technology and storage technology. $\frac{\rho+\pi}{\pi} \theta i_{s}^{\alpha}$ is the measure of fruits from a maturing project created at moment $s$ with investment $i_{s} .(\pi d \tau) e^{-\pi(\tau-s)}$ is the probability that a project created at moment $s$ matures between $\tau$ and $\tau+d \tau$. And $\lambda \frac{\eta}{\mu+\lambda} d s$ is the measure of projects created between moment $s$ and $s+d s$. Similarly, ay $\omega_{\tau}$ is the measure of fruits from the maturing asset of an agent. $(\mu d \tau) e^{-\mu(\tau-s)}$ is the probability that the asset of an agent born at moment $s$ matures between $\tau$ and $\tau+d \tau$. And $\eta d s$ is the measure of agents born between $s$ and $s+d s$. The left-hand side of the resource constraint is the allocation of the available apples to consumption, long-term investment and storage. $(\lambda d \tau) \frac{\eta}{\mu+\lambda}$ is the measure of projects found between $\tau$ and $\tau+d \tau$.

Proposition 5.1. The efficient allocation $\left\{C_{\tau}, m_{\tau}, i_{\tau}\right\}_{\forall \tau \geq t}$ is

$$
\begin{aligned}
i_{\tau} & =i^{*}, \text { such that } \theta \alpha i^{* \alpha-1}=1, \\
m_{\tau} & =0
\end{aligned}
$$

And the efficiency of the economy is characterized solely by investment allocation $i^{*}$

$$
C_{\tau}=\left[\frac{\rho+\pi}{\pi} \theta i^{* \alpha}-i^{*}\right] \frac{\lambda \eta}{\mu+\lambda}+a y \omega_{\tau} \eta
$$

As a benchmark for comparison, in Autarkic allocation, where the repo market is shut down, individual investment, $i$, is constrained to be equal to the amount of apples agents are endowed with and store using the storage technology until they find the project. If the initial endowment is small 
enough so that the marginal return from storing all endowments is greater than $1, \frac{\lambda \theta \alpha m_{0}^{\alpha-1}+\mu}{\rho+\mu+\lambda}>1$, the expected return from investment is $\frac{\lambda \theta m_{0}^{\alpha}+\mu m_{0}}{\rho+\mu+\lambda}$. Otherwise, the storage is such that the expected marginal return from storage is equal to $1, \frac{\lambda \theta \alpha m_{0}^{\alpha-1}+\mu}{\rho+\mu+\lambda}=1$. So, the marginal return from investment in long-term technology is greater than $\frac{\rho+\lambda}{\lambda}$. Therefore, there exists a wedge between the marginal return of the project and the marginal utility of consumption in Autarkic allocation, which is greater than $\frac{\rho+\lambda}{\lambda}-1=\frac{\rho}{\lambda}$. The lower bound of the wedge increases with the search friction to find the long-term project.

In the efficient allocation, in contrast, the wedge between the marginal return of the project investment and the marginal utility of consumption is 0 . The social planner, not subject to enforceability constraints, can allocate consumption goods from maturity projects to new investment. Thus, the optimal investment allocation does not depend on the aggregate risk on the value of collateral. The efficient investment in the long-term project tree does not depend on the value of the collateral asset. As we will see, the efficiency gain from using repo contracts in this environment comes from the transfer of output from maturity projects to investment in new projects.

Another difference between Autarkic allocation and the first-best allocation is the allocation to storage, which can be interpreted as liquidity hoarding. While the storage of each agent in Autarky is equal to her investment in long-term technology, the aggregate storage is 0 in efficient allocation. In other words, it is socially wasteful for agents to hoard liquidity when the social planner is not constrained by market incompleteness. The wedge and inefficiency in the Autarkic economy also comes from the fact that the return on storage technology is low, so it is costly for agents to use the storage technology. If the return on storage technology is equal to the discount factor, the lower bound of the wedge in Autarky would be zero. This is the case, for example, if the storage technology is a fiat currency and the monetary authority follows Friedman rule. ${ }^{23}$

\section{Equilibrium characterization}

With collateral risk and the state-contingent repo contract, default does not happen in equilibrium as long as not all agents default. Next, I add maturity mismatch to the analysis. In the full equilibrium, I will show that maturity mismatch results in repo rollover and equilibrium default.

\footnotetext{
${ }^{23}$ See Lagos and Wright [2005], Berentsen et al. [2007] and Williamson and Wright [2010].
} 
I will also show that default triggers more default in equilibrium because of the undiversified counterparty risk.

\subsection{Characterization of an equilibrium with repo rollover}

With a short-term repo contract not contingent on liquidity arrival, agents borrow from the repo market when they find their long-term investment opportunity, and then they roll over their debt to wait for their long-term investment or collateral asset to mature. But as long as the interest rate $R$ is positive, they cannot roll over their debt infinitely. At certain point, they will reach their debt limit, $\frac{a}{h}$. The dynamics of debt holding in the equilibrium with debt rollover is illustrated in Figure 8(a). Liquidity arrives when the borrower's collateral asset or project matures, which is a random date that could be earlier or later than the moment of reaching the debt limit. The borrower will keep rolling over her debt until she repays is using consumption goods from her trees at maturity or she defaults when she reaches her debt limit.

In this equilibrium, there is a trade-off between default and investment in long-term technology. This trade-off is illustrated in Figure 8(b). As initial borrowing $b^{\prime}$ increases, the moment of reaching the debt limit moves to the left of the timeline. Thus, the probability that the borrower reaches her debt limit before she receives liquidity from maturing trees decreases. If the agent takes on more initial debt, she gains more from long-term investment but is less likely to receive apples from long-term investment or collateral asset before she defaults when she reaches her debt limit.

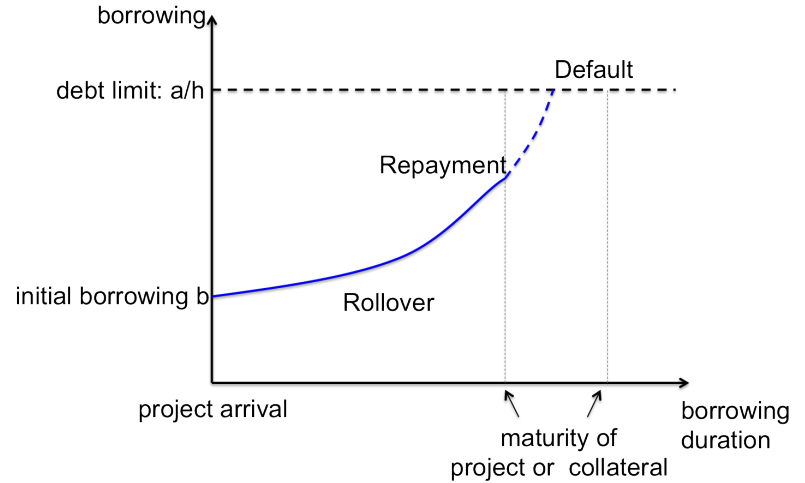

(a) debt rollover

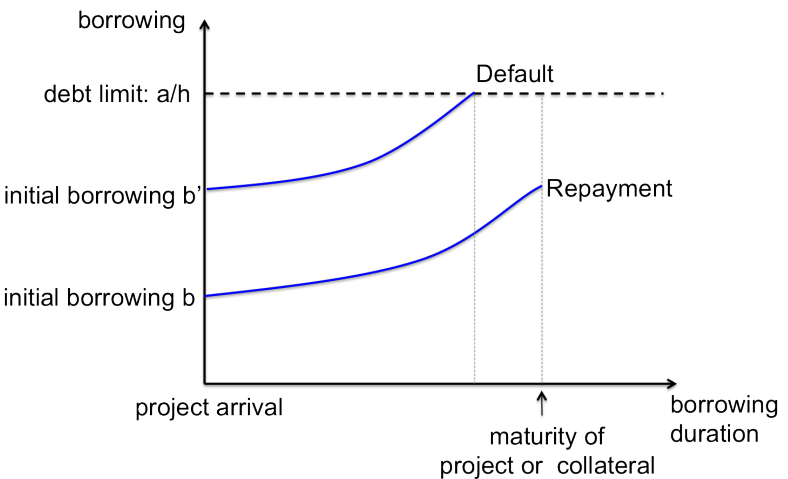

(b) tradeoff for initial borrowing

Figure 8: debt rollover 
The dynamics of other choice variables in the equilibrium with stationary distribution are as follows. Before an agent finds her long-term investment, she keeps lending a constant amount of apples to other agents through the repo market and stores a constant amount of apples. She consumes all interest payments from lending. If she finds a long-term technology, she invests all her apples in storage and repo lending and from her initial borrowing to the long-term technology and stops consuming until the project or her assets mature. If she meets a defaulting agent before her investment, all her lending turns into assets and her consumption drops to zero.

\section{Necessary conditions for an equilibrium with debt rollover}

Lemma 6.1. A necessary and sufficient condition for a borrower with debt holding $b$ to roll over her debt until reaching her debt limit is $\frac{\mu}{\rho+\mu+\chi} y h \geq \frac{\mu+\pi}{\rho+\chi+\mu+\pi-R}$ and $R<\rho+\chi+\mu+\pi$.

Through debt rollover, a borrower can avoid losing collateral assets to lenders. The benefit of avoiding default is higher when haircut is high enough. Lemma 6.1 gives the necessary and sufficient condition for borrowers to roll over their debt holdings.

For equilibrium rollover to take place, a lender must be willing to lend to defaulting borrowers, and she does not default on repo lending to non-defaulting borrowers. This means that when she meets a defaulting borrower, her continuation value from lending to that borrower, $e^{-\rho d t} V^{d}(a+$ $h s, m)$, must be no less than her continuation value from waiting for the next lending opportunity, $e^{-\rho d t} V(a, m, s)$. And when she meets a non-defaulting borrower, her continuation value from waiting for the debt repayment, $e^{-\rho d t} V(a, m, s(1+R d t))$, must be no less than her continuation value from defaulting $e^{-\rho d t} V^{d}(a+h s, m)$.

Lemma 6.2. A sufficient and necessary condition for lenders' strategy in the equilibrium with debt rollover to be optimal is: $V(a, m, s)=V^{d}(a+h s, m)$.

Lemma 6.2 implies that

$$
\mu(y h-1) s=s R+\lambda[U(a, m, s)-U(a+h s, m, 0)]
$$

which shows that haircut compensates for two losses from lending to a defaulting borrower instead of a non-defaulting borrower: the loss of interest payment; and the difference in the continuation 
value when she invests in long-term technology. When the arrival rate of the aggregate shock increases, the heterogeneity increases and haircut may be more likely to satisfy the condition for borrowers to roll over their debt in Lemma 6.1.

\section{Equilibrium characterization}

Lemma 6.3. If the repo contract satisfies the condition in Lemma 6.1, the value function $W(a, 0,-b, i)$ for $b \in \mathbb{R}_{++}$in the equilibrium with debt rollover is characterized by the following differential equation

$$
\begin{aligned}
\rho W(a, 0,-b, i) & =\pi\left[\frac{\rho+\pi}{\pi} f(i)+\frac{\mu}{\rho+\mu+\chi} y a-b-W(a, 0,-b, i)\right] \\
& +\chi[f(i)-W(a, 0,-b, i)]+\mu[f(i)+y a-b-W(a, 0,-b, i)] \\
& +\frac{\partial W(a, 0,-b, i)}{\partial b} b R
\end{aligned}
$$

and boundary condition

$$
W\left(a, 0,-\frac{a}{h}, i\right)=f(i)
$$

The solution to the differential equation is

$$
\begin{aligned}
W(a, 0,-b, i) & =\left[\frac{\mu+\pi}{\rho+\chi+\mu+\pi-R} \frac{1}{h}-\frac{\mu}{\rho+\mu+\chi} y\right] a\left(\frac{h b}{a}\right)^{(\rho+\chi+\mu+\pi) / R} . \\
& -\frac{\mu+\pi}{\rho+\chi+\mu+\pi-R} b+f(i)+\frac{\mu}{\rho+\mu+\chi} y a
\end{aligned}
$$

The initial borrowing at the moment the agent receives an investment opportunity is pinned down by problem (4). The trade-off between losing assets through default and more investment in the long-term project leads to the following result about initial borrowing.

Lemma 6.4. If $h>\frac{\mu+\pi}{\rho+\chi+\mu+\pi-R} \frac{\rho+\mu+\chi}{\mu y}, f^{\prime}(s+m)>\frac{\mu+\pi}{\rho+\chi+\mu+\pi-R}$ and $f^{\prime}\left(s+m+\frac{a}{h}\right)<\frac{\mu}{R} \frac{\rho+\chi+\mu+\pi}{\rho+\mu+\chi} y h-$ $\frac{\mu+\pi}{R}$, an investor's initial borrowing, $b$, is solved by

$$
\frac{\rho+\chi+\mu+\pi}{R}\left(\frac{h b}{a}\right)^{(\rho+\chi+\mu+\pi-R) / R}=\frac{f^{\prime}(s+m+b)-\frac{\mu+\pi}{\rho+\chi+\mu+\pi-R}}{\frac{\mu}{\rho+\mu+\chi} y h-\frac{\mu+\pi}{\rho+\chi+\mu+\pi-R}} .
$$

Initial borrowing $b=0$ if $f(s+m) \leq \frac{\mu+\pi}{\rho+\chi+\mu+\pi-R}$ and $b=\frac{a}{1+h}$ if $f^{\prime}\left(s+m+\frac{a}{h}\right) \geq \frac{\mu}{R} \frac{\rho+\chi+\mu+\pi}{\rho+\mu+\chi} y h-\frac{\mu+\pi}{R}$. 
The first condition for Lemma 6.4 is the sufficient and necessary condition for debt rollover stated in Lemma 6.1. If the marginal return from long-term investment when an agent takes on no initial borrowing is lower than $\frac{\mu+\pi}{\rho+\chi+\mu+\pi-R}$, she will find it not profitable to take on any initial borrowing. If the marginal return from long-term investment when she takes on her initial borrowing up to the debt limit is higher than $\frac{\mu}{R} \frac{\rho+\chi+\mu+\pi}{\rho+\mu+\chi} y h-\frac{\mu+\pi}{R}$, she will borrow up to her debt limit.

Given the initial borrowing, the duration between an agent's initial borrowing and reaching the debt limit, $T(a, b)$, depends on her initial borrowing and asset holding. It is solved by equation $\frac{a}{h}=b e^{R T(a, b)}$. So, $T(a, b)=\frac{1}{R} \ln \left(\frac{a}{h b}\right)$. Given $T(a, b)$, the probability that an agent is able to pay back the debt is

$$
\int_{0}^{T(a, b)}(\mu+\pi) e^{-(\chi+\mu+\pi) t} d t=\frac{\mu+\pi}{\chi+\mu+\pi}\left[1-e^{-(\chi+\mu+\pi) T(a, b)}\right]=\frac{\mu+\pi}{\chi+\mu+\pi}\left[1-\left(\frac{h b}{a}\right)^{\frac{\chi+\mu+\pi}{R}}\right] .
$$

Therefore, the probability of default is $\frac{\chi}{\chi+\mu+\pi}+\frac{\mu+\pi}{\chi+\mu+\pi}\left(\frac{h b}{a}\right)^{\frac{\chi+\mu+\pi}{R}}$, which is increasing in the ratio between initial borrowing and the debt limit, $\hat{b}=\frac{h b}{a}$. From equation (14), $\hat{b}$ is increasing in the marginal return from project investment, $f^{\prime}(s+m+b)$, and decreasing in haircut and dividends from an asset. This reflects the tradeoff between the return from project investment and losing assets through default. So the default probability of an agent is increasing in the productivity of the long-term technology and decreasing in haircut and the dividends of an asset.

The default probability of an agent after initial borrowing also depends on the liquidity of an agent's portfolio. For an agent with portfolio $\left(a+h s^{\prime}, m, s-s^{\prime}\right)$, the following corollary shows that the default probability is increasing in $s^{\prime}$.

Corollary 6.1. Default triggers more default. Counter-party default increases default probability of lenders in the future. For an agent with portfolio $\left(a+h s^{\prime}, m, s-s^{\prime}\right)$,

$$
\frac{d \hat{b}}{d s^{\prime}}>0
$$

Corollary 6.1 is derived from Lemma 6.4. The portfolio of an agent with portfolio $(a, m, s)$ turns into $(a+h s, m, 0)$ after she meets a defaulting agent. So, according to the corollary, an agent whose counterparty defaults before she starts her long-term investment is more likely to default than an agent who has not met a default counterparty when she starts her long-term investment. 


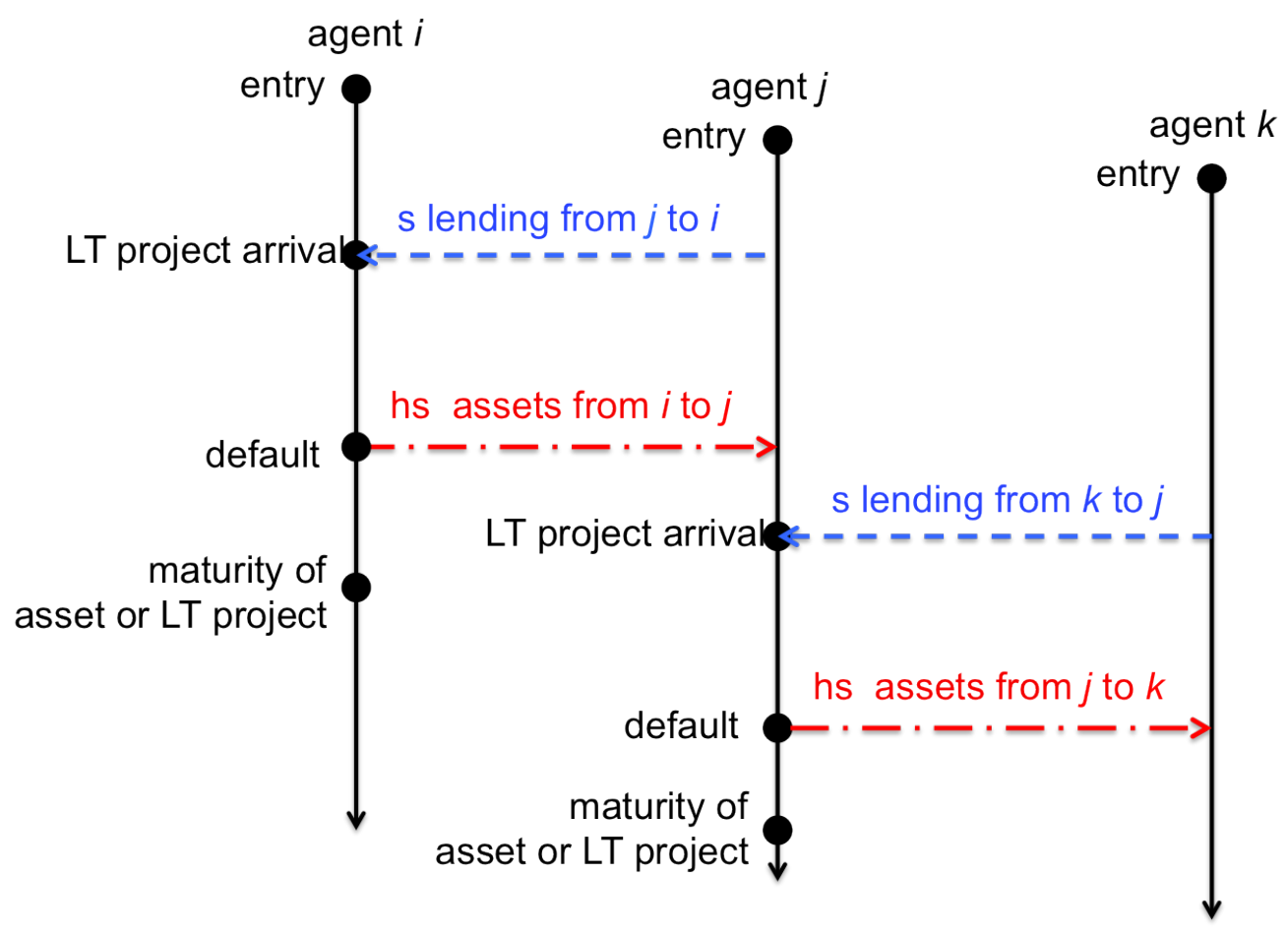

Figure 9: intertemporal chain of borrowing and lending

This implies that counterparty default has an externality on the other agent's default probability. Figure 9 illustrates this externality. Agent $i$ borrows from agent $j$ and delivers her asset holding to agent $j$ upon default. This increases agent $j$ 's default probability when she borrows from agent $k$, among other agents, to invest in her long-term project. So, agent $j$ is more likely to deliver her assets to agent $k$ upon default. As we can see from the inter-temporal chain of reactions, the default of one agent increases the default probability of those agents who lend to her, which may affect the default probability of those who lend to agent $j$ 's. This intertemporal chain is reminiscent of Kiyotaki and Moore [1997b], which studies the propagation of shocks through credit chains. In my model, shocks to agents' portfolio - making their portfolio less liquid - are contagious. The increase in the probability of default passes on from a defaulting borrower to her lenders or, so to speak, borrowers-to-be. The risk-taking of an individual borrower, therefore, adds to the risk of the whole system. I will explore this type of contagion more in the section on dynamics.

Proposition 6.1. A stationary equilibrium with debt rollover must satisfy conditions in Lemma 6.1 and Lemma 6.2. The equilibrium can be summarized by interest rate $R$, haircut $h$, default rate 
$\delta$, the portfolio choice of active lenders, $(m, s)$, the initial borrowing of active lenders, $b_{1}$ and the initial borrowing of deactivated lenders, $b_{0}$, in the following system of equations,

$$
\begin{aligned}
\left(\frac{h b_{1}}{a_{0}}\right)^{(\rho+\chi+\mu+\pi-R) / R} & =\frac{R}{\rho+\chi+\mu+\pi} \frac{f^{\prime}\left(m_{0}+b_{1}\right)-\frac{\mu+\pi}{\rho+\chi+\mu+\pi-R}}{\frac{\mu}{\rho+\mu+\chi} y h-\frac{\mu+\pi}{\rho+\chi+\mu+\pi-R}} \\
\left(\frac{h b_{0}}{a_{0}+h s}\right)^{(\rho+\chi+\mu+\pi-R) / R} & =\frac{R}{\rho+\chi+\mu+\pi} \frac{f^{\prime}\left(m+b_{0}\right)-\frac{\mu+\pi}{\rho+\chi+\mu+\pi-R}}{\frac{\mu}{\rho+\mu+\chi} y h-\frac{\mu+\pi}{\rho+\chi+\mu+\pi-R}} \\
\mu(y h-1) s & =s R+\lambda[U(a, m, s)-U(a+h s, m, 0)] \\
\delta & =\frac{B^{d}}{B}, \\
\frac{1}{\mu+\lambda+\delta} s & =B, \\
(m, s) & \in \arg \max _{m+s \leq m_{0}, m \geq 0, s \geq 0} V(a, m, s) .
\end{aligned}
$$

where $B$ denotes total borrowing, $B^{d}$ denotes the borrowing from defaulting borrowers.

$$
B=\frac{\lambda}{\mu+\lambda+\delta} b_{1} \int_{0}^{T_{1}} e^{(R-\mu-\pi) s} d s+\frac{\delta}{\mu+\lambda} \frac{\lambda}{\mu+\lambda+\delta} b_{0} \int_{0}^{T_{0}} e^{(R-\mu-\pi) s} d s
$$

and

$$
B^{d}=\frac{\lambda}{\mu+\lambda+\delta} b_{1} e^{(R-\mu-\pi) T_{1}}+\frac{\delta}{\mu+\lambda} \frac{\lambda}{\mu+\lambda+\delta} b_{0} e^{(R-\mu-\pi) T_{0}},
$$

where $T_{0}=\frac{1}{R} \ln \left(\frac{h b_{0}}{a_{0}+h s}\right)$ and $T_{1}=\frac{1}{R} \ln \left(\frac{h b_{1}}{a_{0}}\right)$.

Equations (15) and (16) are the optimality conditions for the initial borrowing of active and deactivated lenders when they find their long-term projects. Equation (17) is the condition for lenders to be willing to roll over the debt. Equation (18) pins down the equilibrium default rate, which is the ratio of the demand for funding from defaulting borrowers and the total demand of borrowers. Equation (19) is the market-clearing condition. Equation (20) pins down the portfolio choice of active lenders.

\subsection{The effect of collateral risk}

As the equilibrium of the full model depends on two key features - collateral risk and maturity mismatch - let us take one step back before looking at the comparative statics of the full model. In this subsection, I study the effect of collateral risk on liquidity hoarding and cash in the repo market by studying a state-contingent debt contract with an exogenous borrowing constraint. By 
shutting down maturity mismatch, we can focus on the effect of collateral risk on the equilibrium outcome. In the next subsection, I will go one step further to characterize the whole equilibrium with maturity mismatch because of using short-term repo contracts.

\subsubsection{Equilibrium with state-contingent repo contracts}

The repayment of the repo contract I consider in this subsection is contingent on the arrival of liquidity when the borrower's collateral asset or long-term project matures. ${ }^{24}$ With state-contingent repo contracts, there are two symmetric equilibria, one in which no agents will default when they start borrowing and another in which all agents default immediately when they start borrowing.

Proposition 6.2. Suppose that $\min \left\{f^{\prime}\left(m_{0}+\frac{a_{0}}{h}\right), \frac{\mu y}{\rho+\chi+\mu} h\right\}>\frac{(\mu+\pi)(1+R)}{\rho+\chi+\mu+\pi}$, then, there exists a unique stationary equilibrium with the state-contingent repo contract characterized by the following system of equations,

$$
\begin{aligned}
R & =\frac{\chi}{\mu+\pi} \frac{\lambda}{\rho+\lambda} f^{\prime}(m), \\
m_{0}-m & =\frac{\lambda}{\mu+\pi} \frac{a_{0}}{(1+R) h},
\end{aligned}
$$

Proof of the proposition is left to the Appendix. The assumption in the proposition ensures that an agent who borrows to invest in her long-term project would borrow against all her collateral assets because the return from project investment is high enough. According to proposition 6.2, the interest rate increases in equilibrium liquidity hoarding of agents waiting for their own investment opportunities, taking parameter values as given. In the next proposition, I do some comparative statics.

Proposition 6.3. Under the assumption in Proposition 6.2,

1. $\frac{\partial m}{\partial \chi}>0, \frac{\partial R}{\partial \chi}>0, \frac{\partial i}{\partial \chi}>0$

2. $\frac{\partial m}{\partial \pi}>0, \frac{\partial R}{\partial \pi}<0, \frac{\partial i}{\partial \pi}>0$.

Proposition 6.3 gives the comparative statics with respect to collateral risk and the maturity of the project. When collateral risk increases, agents waiting for their investment opportunity

\footnotetext{
${ }^{24}$ Without loss of generality, I assume that the liquidity at the maturity of either the project or the collateral asset is enough to repay all the debt.
} 
refrain from inter-bank lending and increase storage, as consumptions good in storage would be the only resource available when the economy is in the bad state. As a result, funding for the repo market dries up. Thus, the interest rate of the repo contract increases and investment in long-term investment drops. When the maturity of the project decreases, liquidity from maturing projects flows more frequently to lenders and, subsequently, results in more project investment and liquidity hoarding. With more funding available to lenders, the tension between liquidity hoarding and project investment is tempered. Consequently, both liquidity hoarding and investment increase and interest rates drop.

\subsection{Market liquidity, solvency and balance sheet of financial intermediaries}

In this subsection, I examine the comparative statics of the rollover equilibrium, keeping the expected payoff from dividends from collateral fixed. ${ }^{25}$ This way, the effect of collateral risk on the rollover equilibrium will be clearer. ${ }^{26}$

Figure 10 illustrates how collateral risk affects the liquidity of the repo market and the solvency of financial intermediaries. Figure 11 illustrates how collateral risk affects the aggregated balance sheet of financial intermediaries. When the arrival rate of devaluation shock increases, banks hoard more liquidity in their storage account and refrain from lending to other banks. This increases the interest rate and haircut in the market, which is consistent with the analytical results we derive in an environment without maturity mismatch. With maturity mismatch between investment and liability, borrowers are more likely to default, facing the higher haircut and interest rates. The increase in default rate would further increase the haircut and interest rates.

The disfunctioning of the repo market is reflected in the aggregate long-term investment and leverage ratio, as collateral risk, the long-term investment and therefore the aggregate output of the economy drops. And Figure 11 shows that repo lending contributes less to long-term investment, and more investment uses funding from storage.

In Figure 11, the increase in storage, which represents liquidity hoarding, and the decrease in repo lending as collateral risk increases are not completely substitutable. As collateral risk increases, default is more likely, rollover is harder and lenders have more illiquid collateral asset but less liquid

\footnotetext{
${ }^{25}$ When I increase devaluation shock $\chi$, I also increase dividend payment from a collateral tree when the economy is in the good state. So the dividend payment $y$ satisfies the following condition, $\frac{y}{\rho+\mu+\chi}=\frac{y_{0}}{\rho+\mu+\chi_{0}}$.

${ }^{26}$ Parameter values used in the comparative statics and transition dynamics is listed in Table 2 in the appendix.
} 

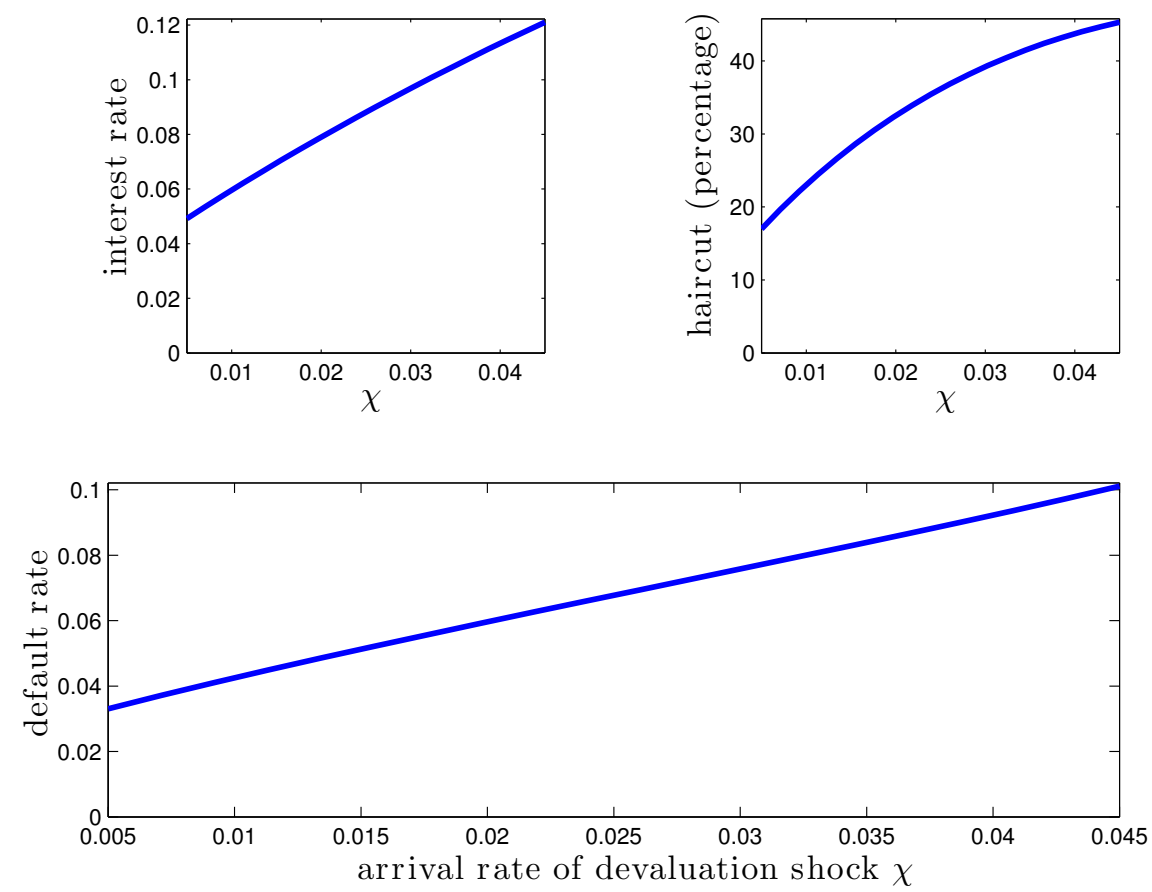

Figure 10: Collateral risk and the liquidity of the repo market and solvency of financial intermediaries.

asset. As a result, the sum of repo lending and storage, which is what we call short-term asset, decreases. Notice that with the state-contingent repo contract, the sum of repo lending and reserve is constant. The decrease in reflects the increase in default rate. When debt rollover is harder, the value of repo lending drops and illiquid collateral asset held by agents waiting for their investment opportunities increases.

While comparative statics in the model resemble a Kiyotaki-Moore type of model assuming exogenous borrowing constraint, the constraint in my model is endogenous and depends on the collateral risk and the contract structure. For example, the haircut for the overnight repo contract would be higher than that for the state-contingent repo contract. The endogenous haircut is especially relevant when we study equilibrium dynamics, where the borrowing constraint implied from haircut will move endogenously along the dynamic path. I now turn to characterize the transition dynamics triggered by an unexpected shock to the riskiness of collateral assets. 

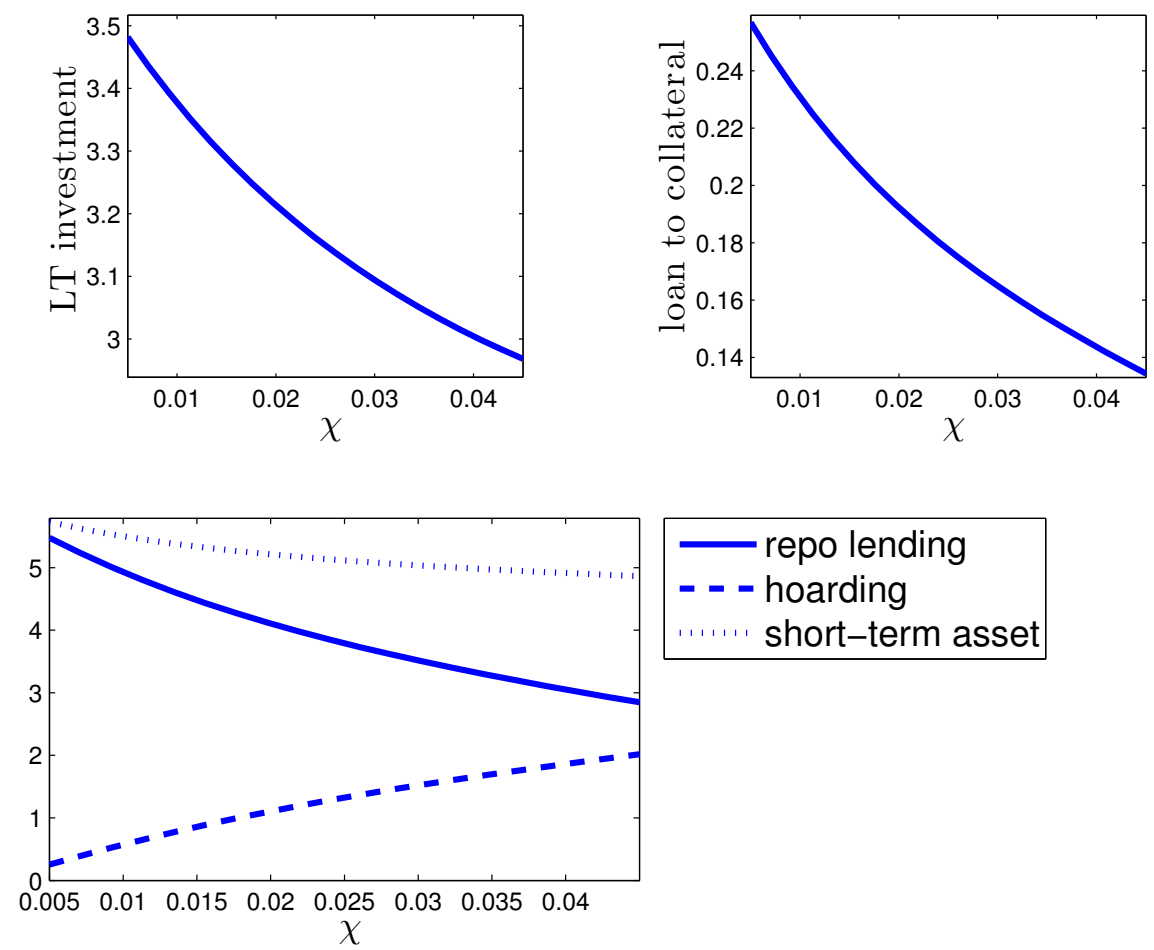

Figure 11: Credit risk and the aggregated balance sheet of the securitized banking system.

\section{Equilibrium dynamics}

In this section, I characterize the transition dynamics when agents' expectations about the collateral risk become more pessimistic. The exercise is intended to capture the transition dynamics triggered by a shock similar to the one that we experienced during the great recession. More importantly, it will help us understand the stability of the shadow banking system to shocks to collateral risk.

I assume that the economy before $t=0$ is the steady-state equilibrium with $\omega_{t}=1$, with the parameter values given in Table 2. At $t=0, \chi$ switches from 0.01 to 0.02 . The algorithm to compute the transition dynamics is in the Appendix.

Figure 13 shows the transition dynamics for the liquidity of the repo market and the solvency of financial intermediaries. Figure 14 illustrates the transition dynamics for the aggregated balance sheet of financial intermediaries in the securitized banking system. And Figure 15 illustrates the transition dynamics of output and investment and the impact of the financial crisis on the real economy. ${ }^{27}$

\footnotetext{
${ }^{27}$ In Figure 14 and Figure 15, I normalized the values of the variables in the initial steady state to one.
} 
The stability can be measured by two dimensions: initial response and persistence of the impact.

\section{Initial response of the shadow banking system}

Let's first look at the initial response of the economy to the shift in expectations. At the moment the expectations shift, haircut increases discontinuously and overshoots to a level even higher than the haircut in the new steady state. This means that the debt limit that borrowers face given their collateral asset holding drops discontinuously. As a result, borrowers with debt holdings above the new debt limit but below the old debt limit are forced to default at $t$. The mass of default drains the funding available in the repo market. Thus, the aggregate amount of repo lending drops, and the massive initial default shows up in the discontinuous drop in repo lending in Figure 14. The overshooting of haircut increases the probability of the initial default. The figure shows that about $25 \%$ of outstanding repo borrowing defaults at the moment the shock hits the economy.

The hike in haircut reflects the fact that the massive default drains liquidity from the market as lenders' liquid funding is replaced by illiquid collateral assets from defaulting borrowers. With less funding available for both liquidity hoarding and repo lending, the interest rate overshoots.

As new entrants bring in more liquidity over time, the interest rates and haircut drops, and liquidity hoarding increases. But the crisis is not over yet. The counterparty default risk remains high. The overshooting in the default rate drains the financial system's liquidity and triggers more default in the future. This leads us to the persistence of the crisis.

\section{Persistence of the impact of the shock}

Massive initial default and high default rate related to the debt overhang for borrowers who started borrowing before the crisis leads to more default in the future. We can see that the overshooting in drop in investment, repo borrowing or lending and depressed liquidity hoarding persist for a long period. If we think of a period as a quarter, it would still take more than ten years for the economy to recover from the crisis and recover to the output level in the new steady state.

The disruption in the financial system has a big impact on investment and output of the economy. Figure 15 shows that total investment drops by $20 \%$ immediately after the shock to collateral risk and eventually drops by about $12 \%$. The aggregate output responds with delay because it takes time for investment in new projects to yield output. Because of the contagion 
effect and the initial massive default, the decrease in output also overshoots. The maximum drop is about $7 \%$, after which the output recovers a little, and the output at the new steady state is about $5 \%$ lower than at the old steady state.

The fluctuation on the transition path is related to the massive initial default and the outstanding repo borrowing when the shock hits the economy. Before the shock, investors borrow more without worrying too much about default because of lower interest rates and lower haircut. When collateral risk increases unexpectedly, borrowers with outstanding repo borrowing appear to be over-borrowing and, therefore, likely to default under the higher haircut and interest rate. The hike in the default rate leads to fluctuations in market liquidity and the balance sheet of the shadow banking system. Figure 12 illustrates the contagion of counterparty default. It shows two components of the demand for repo borrowing: one (the blue line) from investors who are still waiting for their investment opportunities but have illiquid portfolios (more collateral asset and less consumption goods than their initial endowment) at time zero, another (the red line) from the rest of the borrowers, including those who started borrowing before time zero and were not forced to default at time zero, those with liquid portfolio before they start borrowing and those with illiquid portfolio before start borrowing because they experienced counterparty default after time zero. The first component first increases and then, declines, with a sharp turn. The turn takes place when investors whose demand for repo borrowing is included in the first component start to default. The peak helps us see more clearly the effect of intertemporal contagion through default. Since default triggers more default, default rate for this group of investors remain high. And because of the massive initial default, the high default rate of this group shows up as a spike in the aggregate default rate shown in Figure 13. The second component includes those investors who started borrowing before time zero and were not forced to default at time zero. The demand from those investor constitutes a debt overhang problem: Since they started borrowing when the economy was in the initial steady-state equilibrium, in which agents expect that collateral risk is low, they borrow more than they would have if they had realized the risk; this means the default rate for this group of borrowers with over-hang debt will be high. Since there are two types of borrowers with different initial borrowings and debt limits in the steady state before the shock to expectation hits the economy, the distribution of borrowers is a combination of two continuous distributions. This is why we can see two distinct peaks in default rate at the beginning of the 


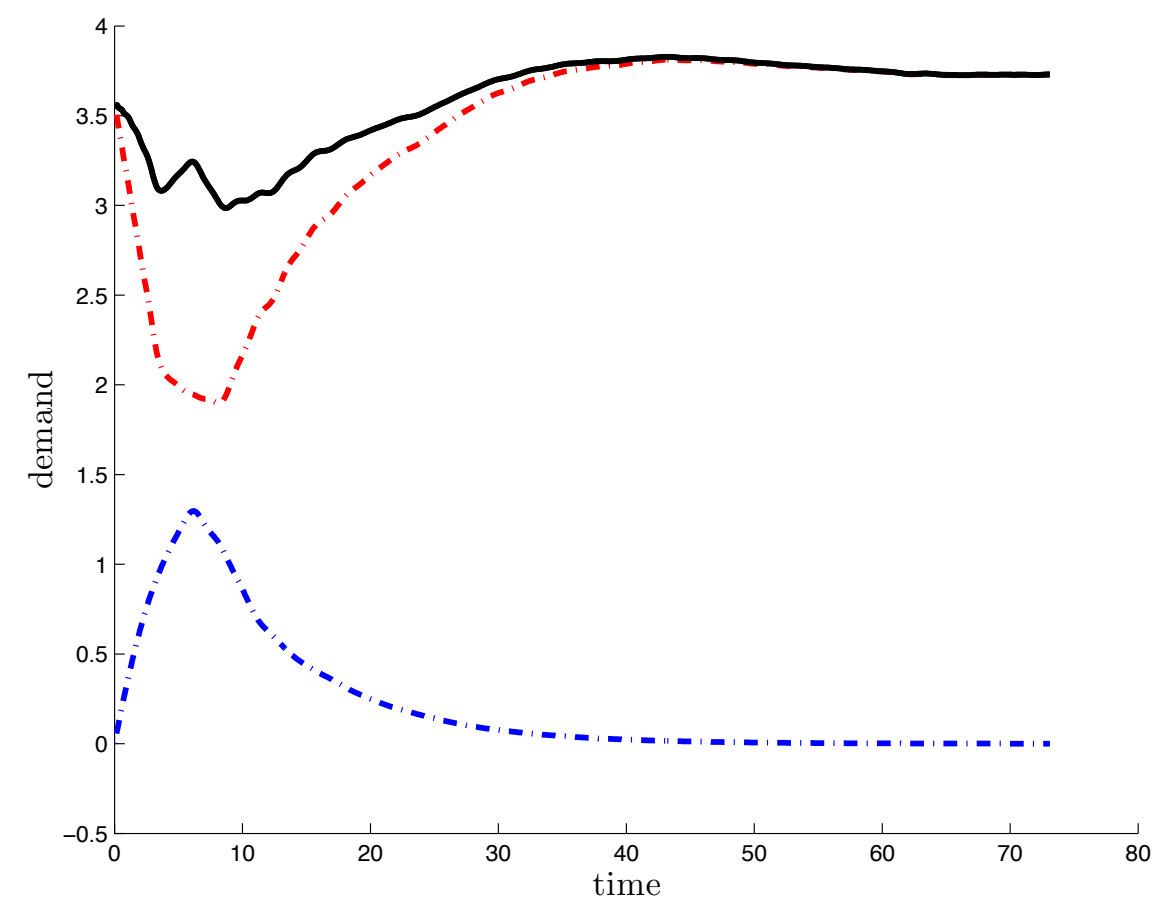

Figure 12: Decomposition of repo demand

transition path, before investors in the first group start to default.

Overall, the debt overhang and initial massive default lead to fluctuations in default rate and the hikes in default rate after time zero leads to more default on the dynamic path. The contagion of counterparty default and illiquidity of lenders' portfolio leads to persistent overshooting in default rate, haircut, interest rates, leverage ratio, investment and output.

After the breakout of crisis in 2007, the Federal Reserve stepped in to provide liquidity to the dealer banksAdrian et al. [2009]. In daily news, many argue whether bailing out "too big to fail" dealer banks is a good idea. From this exercise, we can see a counterfactual equilibrium dynamics for what would have happened after the shift in expectation when the Federal Reserve Bank had not stepped in. The mass of default would trigger over-shooting in haircut and interest rate and misallocation and fluctuation of lenders' funding between repo lending and reserve. 

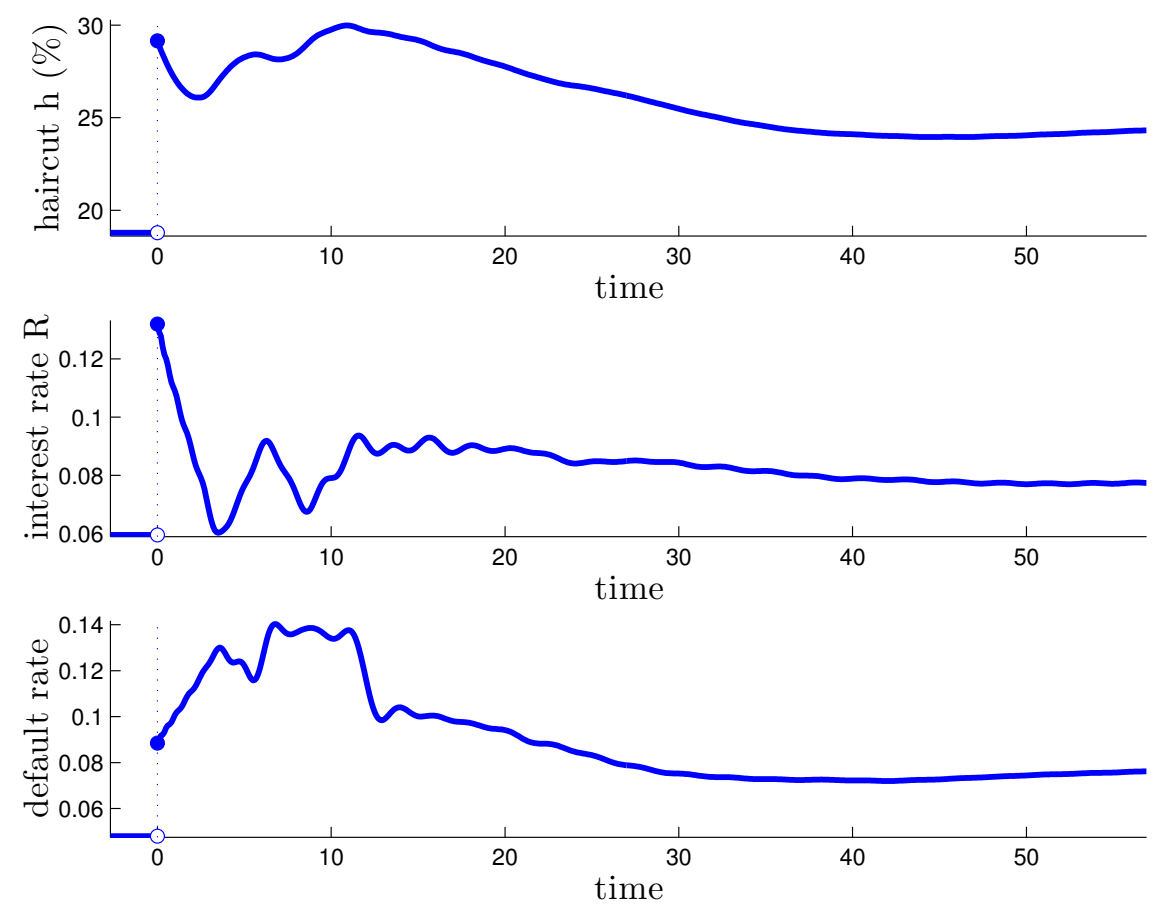

Figure 13: Equilibrium dynamics of the liquidity of the repo market and solvency of financial intermediaries, when collateral risk increases unexpectedly. 

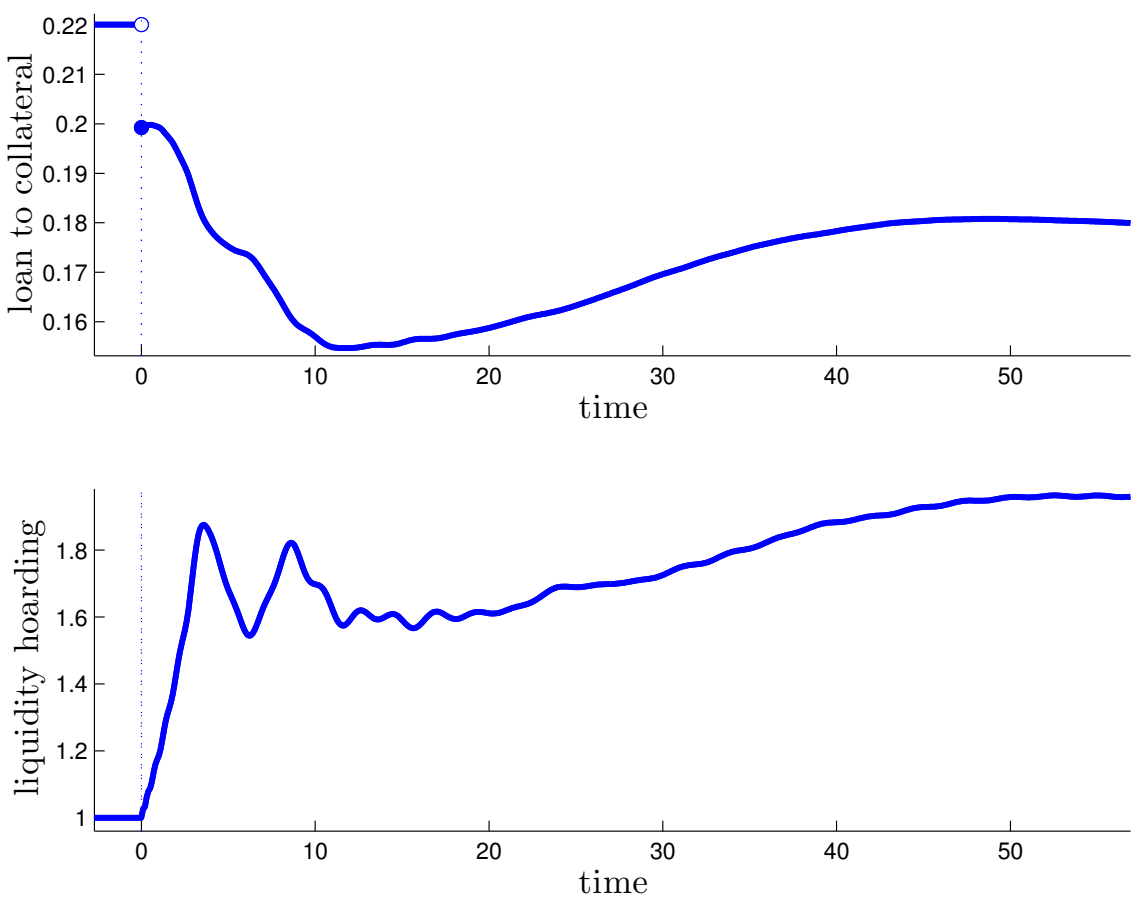

Figure 14: Equilibrium dynamics of the aggregate balance sheet of the securitized banking system, when collateral risk increases unexpectedly. 

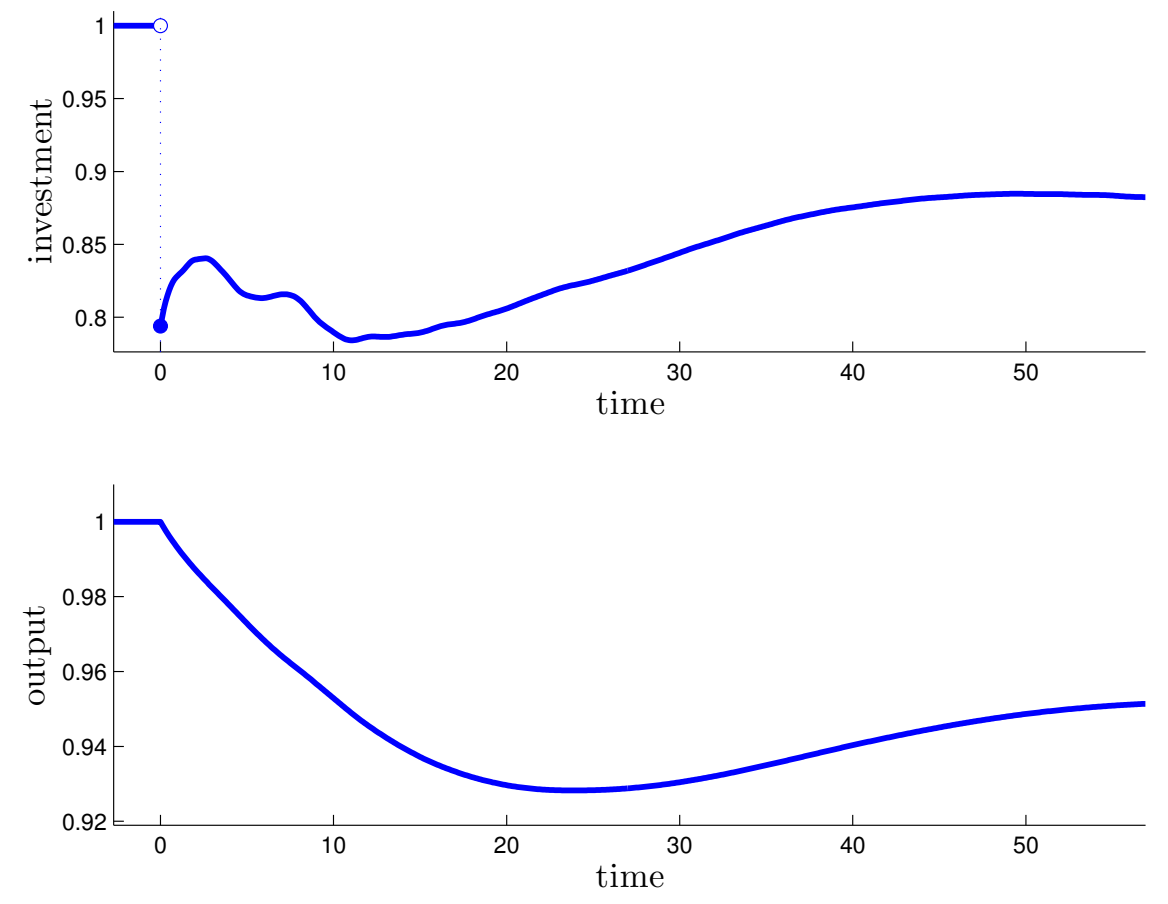

Figure 15: Equilibrium dynamics of investment and output, when collateral risk increases unexpectedly. 


\section{Conclusion}

In this paper, I build a dynamic model to study the efficiency and stability of the shadow banking system. I show that collateral risk leads to an increase in counterparty default risk in the equilibrium with repo rollover. Counterparty default drains liquidity from the repo market and reduces output. By studying the dynamic equilibrium triggered by a shock to collateral risk, I show that the shift in collateral risk could be an important contributor to the disruptions in the repo market and the shadow banking system we observed during the 2007-2008 financial crisis. And the shadow banking system is vulnerable to shifts in market participants' perception of the collateral risk in two senses. First, a small shift in the market belief could trigger a massive initial default. Second, the effect of the shock is long-lasting. The exercise shows that the externality of counterparty default has important implications for the efficiency and stability of the shadow banking system and related government policies.

\section{References}

Viral V Acharya and Alberto Bisin. Counterparty risk externality: Centralized versus over-thecounter markets. Journal of Economic Theory, 2013.

Tobias Adrian and Hyun Song Shin. Liquidity and leverage. Journal of Financial Intermediation, 19(3):418-437, 2010.

Tobias Adrian, Christopher Burke, and James McAndrews. The federal reserve's primary dealer credit facility. Current Issues in Economics and Finance, 15(4), 2009.

Gara Afonso and Ricardo Lagos. Trade dynamics in the market for federal funds. FRB of New York Staff Report, (549), 2012.

Franklin Allen and Douglas Gale. Financial contagion. Journal of Political Economy, 108(1):1-33, 2000.

Franklin Allen and Douglas Gale. Bubbles and crises. The Economic Journal, 110(460):236-255, 2001. 
Aleksander Berentsen, Gabriele Camera, and Christopher Waller. Money, credit and banking. Journal of Economic Theory, 135(1):171-195, 2007.

Ben Bernanke and Mark Gertler. Agency costs, net worth, and business fluctuations. The American Economic Review, pages 14-31, 1989.

Jean-Marc Bottazzi, Jaime Luque, and Mário R Páscoa. Securities market theory: Possession, repo and rehypothecation. Journal of Economic Theory, 147(2):477-500, 2012.

Markus Brunnermeier and Yuliy Sannikov. A macroeconomic model with a financial sector. National Bank of Belgium Working Paper, (236), 2012.

Markus K Brunnermeier and Martin Oehmke. The maturity rat race. The Journal of Finance, 68 (2):483-521, 2013 .

Braz Camargo and Benjamin Lester. Trading dynamics in decentralized markets with adverse selection. Unpublished Manuscript, 2011.

Jonathan Chiu and Thorsten V Koeppl. Trading dynamics with adverse selection and search: Market freeze, intervention and recovery. Intervention and Recovery (April 1, 2011), 2011.

Adam Copeland, Darrell Duffie, Antoine Martin, and Susan McLaughlin. Key mechanics of the us tri-party repo market. Economic Policy Review, pages 17-28, 2012.

Tri Vi Dang, Gary Gorton, and Bengt Holmstrom. Opacity and the optimality of debt for liquidity provision. Manuscript Yale University, 2009.

Tri Vi Dang, Gary Gorton, and Bengt Holmström. Ignorance, debt and financial crises. Unpublished, Yale SOM, 2012.

Douglas W Diamond and Philip H Dybvig. Bank runs, deposit insurance, and liquidity. The Journal of Political Economy, pages 401-419, 1983.

Darrell Duffie. The failure mechanics of dealer banks. The Journal of Economic Perspectives, 24 (1):51-72, 2010 .

Darrell Duffie, Nicolae Gârleanu, and Lasse Heje Pedersen. Over-the-counter markets. Econometrica, 73(6):1815-1847, 2005. 
Emmanuel Farhi and Jean Tirole. Information, tranching and liquidity. 2012.

Michael Fleming and Kenneth Garbade. Explaining settlement fails. Current Issues in Economics and Finance, 11(9):1-7, 2005.

Ana Fostel and John Geanakoplos. Endogenous leverage in a binomial economy: The irrelevance of actual default. 2012.

Jacob A Frenkel and Boyan Jovanovic. On transactions and precautionary demand for money. The Quarterly Journal of Economics, 95(1):25-43, 1980.

Douglas Gale and Tanju Yorulmazer. Liquidity hoarding. Theoretical Economics, 8(2):291-324, 2013.

Kenneth Garbade. The evolution of repo contracting conventions in the 1980s. Economic Policy Review, 12(1), 2006.

John Geanakoplos and William Zame. Collateralized security markets. unpublished. Earlier versions, 2002:2005, 1997.

Nicola Gennaioli, Andrei Shleifer, and Robert W Vishny. A model of shadow banking. The Journal of Finance, 2013.

Mark Gertler and Nobuhiro Kiyotaki. Banking, liquidity and bank runs in an infinite-horizon economy. Technical report, National Bureau of Economic Research, 2013.

Gary Gorton. The subprime panic. European Financial Management, 15(1):10-46, 2009.

Gary Gorton and Andrew Metrick. Securitized banking and the run on repo. Journal of Financial Economics, 104(3):425-451, 2012a.

Gary B Gorton and Andrew Metrick. Haircuts. Technical report, National Bureau of Economic Research, 2009.

Gary B Gorton and Andrew Metrick. Who ran on repo? Technical report, National Bureau of Economic Research, 2012b. 
Gary B Gorton and Guillermo Ordonez. Collateral crises. Technical report, National Bureau of Economic Research, 2012.

Zhiguo He, In Gu Khang, and Arvind Krishnamurthy. Balance sheet adjustments during the 2008 crisis. IMF Economic Review, 58(1):118-156, 2010.

Klaus-Peter Hellwig and Shengxing Zhang. Market runs: Liquidity and the value of information. 2012.

Peter Hördahl and Michael King. Developments in repo markets during the financial turmoil. BIS Quarterly Review, pages 37-53, 2008.

Timothy J Kehoe and David K Levine. Debt-constrained asset markets. The Review of Economic Studies, 60(4):865-888, 1993.

Nobuhiro Kiyotaki and John Moore. Credit cycles. Journal of Political Economy, 105(2), 1997a.

Nobuhiro Kiyotaki and John Moore. Credit chains. 1997b.

Nobuhiro Kiyotaki and John Moore. Evil is the root of all money. The American Economic Review, 92(2):62-66, 2002.

Narayana R Kocherlakota. Risky collateral and deposit insurance. Advances in Macroeconomics, $1(1), 2001$.

A. Krishnamurthy, S. Nagel, and D. Orlov. Sizing up repo. Technical report, National Bureau of Economic Research, 2012.

Ricardo Lagos and Guillaume Rocheteau. Liquidity in asset markets with search frictions. Econometrica, 77(2):403-426, 2009.

Ricardo Lagos and Randall Wright. A unified framework for monetary theory and policy analysis. Journal of Political Economy, 113(3):463-484, 2005.

Antoine Martin, David Skeie, Von Thadden, et al. Repo runs. In AFA 2011 Denver Meetings Paper, 2011. 
John Moore. Leverage stacks and the financial system. Ross Prize Lecture to the Foundation for the Advancement of Research in Financial Economics, 2011.

Zoltan Pozsar, Tobias Adrian, Adam Ashcraft, and Hayley Boesky. Shadow banking, 2013. URL http://www. newyorkfed.org/research/epr/2013/0713adri.html.

Thomas Sargent. Liquidity? Keynote address for Bank of Korea Conference, 2013.

Manmohan Singh and James Aitken. The (sizable) role of rehypothecation in the shadow banking system. International monetary fund (IMF), 2010.

Stephen Williamson and Randall Wright. New monetarist economics: Models. Handbook of Monetary Economics, 3:25-96, 2010.

Stephen D Williamson. Scarce collateral, the term premium, and quantitative easing. 2013. 


\begin{tabular}{c|c||c|c}
\hline parameter & value & parameter & value \\
\hline \hline$\rho$ & 0.03 & $\mu$ & 0.033 \\
\hline$\lambda$ & 0.09 & $\pi$ & 0.1 \\
\hline$\chi$ & 0.01 & $y$ & 1 \\
\hline$\theta$ & 4 & $\alpha$ & 0.38 \\
\hline$a_{0}$ & 4.17 & $m_{0}$ & 1 \\
\hline
\end{tabular}

Table 2: Parameter values used in numerical exercises

\section{A Laws of motion}

First if $\omega_{t}=1$, the law of motion of $F_{0 t}(a, m, s)$ is

$$
\begin{aligned}
d F_{0 t}^{1}(a, m, s) & =-\int \mathbb{I}\left(\begin{array}{l}
a^{\prime} \leq a, \\
\tilde{m}_{0 t}\left(a^{\prime}, m^{\prime}, s^{\prime}\right) \leq m, \\
\tilde{s}_{0 t}\left(a^{\prime}, m^{\prime}, s^{\prime}\right) \leq s
\end{array}\right)(\mu+\lambda) d t\left(1-\tilde{d}_{0 t}\left(a^{\prime}, m^{\prime}, s^{\prime}\right)\right) d F_{0, t-d t}^{1}\left(a^{\prime}, m^{\prime}, s^{\prime}\right) \\
& -\int \mathbb{I}\left(\begin{array}{l}
a^{\prime} \leq a, \\
m^{\prime} \leq m, \\
s^{\prime} \leq s
\end{array}\right) \tilde{d}_{0 t}\left(a^{\prime}, m^{\prime}, s^{\prime}\right) d F_{0, t-d t}^{1}\left(a^{\prime}, m^{\prime}, s^{\prime}\right) \\
& +\int \mathbb{I}\left(\begin{array}{l}
a^{\prime} \leq a, \\
\tilde{m}_{0 t}\left(a^{\prime}, m^{\prime}, s^{\prime}\right) \leq m, \\
\tilde{s}_{0 t}\left(a^{\prime}, m^{\prime}, s^{\prime}\right) \leq s
\end{array}\right) \delta_{t} \mathbb{I}_{s^{\prime}>0} d t\left(1-\tilde{z}_{0 t}\left(a^{\prime}, m^{\prime}, s^{\prime}\right)\right) d F_{0, t-d t}^{1}\left(a^{\prime}, m^{\prime}, s^{\prime}\right) \\
+ & =\left(\begin{array}{l}
a^{\prime}+h_{t} s^{\prime} \leq a, \\
\tilde{m}_{0 t}\left(a^{\prime}, m^{\prime}, s^{\prime}\right) \leq m, \\
\tilde{s}_{0 t}\left(a^{\prime}, m^{\prime}, s^{\prime}\right) \leq s
\end{array}\right) \tilde{d}_{0 t}\left(a^{\prime}, m^{\prime}, s^{\prime}\right) d F_{0, t-d t}^{1}\left(a^{\prime}, m^{\prime}, s^{\prime}\right) \\
+ & \left(\begin{array}{l}
a \leq a_{0}, \\
\tilde{m}_{0 t}\left(a_{0}, 0, m_{0}\right) \leq m, \\
\tilde{s}_{0 t}\left(a_{0}, 0, m_{0}\right) \leq s
\end{array}\right)
\end{aligned}
$$

The first component in equation 23 is the outflow of maturing assets and agents receiving an investment opportunity, conditional on the agent not defaulting. Agents with maturing assets consumes and leave the economy. Agents with incoming projects flow to the measure $F_{1 t}$. The second component is the outflow of defaulting agents from type $\left(a^{\prime}, m^{\prime}, s^{\prime}\right)$ to other types. The third component is the inflow of agents who meet defaulting borrowers at $t-d t$ but do not accept them. 
The fourth component is the inflow from defaulting agents. The last component is the inflow from newcomers at $t-d t$.

$$
\begin{aligned}
d F_{d t}^{1}(a, m) & =-\int \mathbb{I}\left(\begin{array}{l}
a^{\prime} \leq a, \\
\tilde{m}_{d t}\left(a^{\prime}, m^{\prime}\right) \leq m, \\
\tilde{s}_{d t}\left(a^{\prime}, m^{\prime}\right) \leq s
\end{array}\right)(\mu+\lambda) d t d F_{0, t-d t}^{1}\left(a^{\prime}, m^{\prime}\right) \\
& +\int \mathbb{I}\left(\begin{array}{l}
a^{\prime}+(1+h) \tilde{s}_{0 t}\left(a^{\prime}, m^{\prime}, s^{\prime}\right) \leq a, \\
\tilde{m}_{0 t}\left(a^{\prime}, m^{\prime}, s^{\prime}\right) \leq m, \\
\tilde{s}_{0 t}\left(a^{\prime}, m^{\prime}, s^{\prime}\right) \leq s
\end{array}\right) \delta_{t} \mathbb{I}_{s^{\prime}>0} d t \tilde{z}_{0 t}\left(a^{\prime}, m^{\prime}, s^{\prime}\right) d F_{0, t-d t}\left(a^{\prime}, m^{\prime}, s^{\prime}\right)
\end{aligned}
$$

Similarly, if $\omega_{t}=1$, the law of motion of $F_{1 t}(a, m, s, i)$ is 


$$
\begin{aligned}
& d F_{1 t}(a, m, s, i)=-\int \mathbb{I}\left(\begin{array}{l}
a^{\prime} \leq a, \\
\tilde{m}_{1 t}\left(a^{\prime}, m^{\prime}, s^{\prime}\right) \leq m, \\
\tilde{s}_{1 t}\left(a^{\prime}, m^{\prime}, s^{\prime}\right) \leq s, \\
i^{\prime} \leq i
\end{array}\right)(\mu+\pi) d t\left(1-\tilde{d}_{1 t}\left(a^{\prime}, m^{\prime}, s^{\prime}, i^{\prime}\right)\right) d F_{1, t-d t}\left(a^{\prime}, m^{\prime}, s^{\prime}, i^{\prime}\right) \\
& -\int \mathbb{I}\left(\begin{array}{l}
a^{\prime} \leq a, \\
m^{\prime} \leq m, \\
s^{\prime} \leq s, \\
i^{\prime} \leq i
\end{array}\right) \tilde{d}_{1 t}\left(a^{\prime}, m^{\prime}, s^{\prime}, i^{\prime}\right) d F_{1, t-d t}\left(a^{\prime}, m^{\prime}, s^{\prime}, i^{\prime}\right) \\
& +\int \mathbb{I}\left(\begin{array}{l}
a^{\prime}+h_{t} \tilde{s}_{1 t}\left(a^{\prime}, m^{\prime}, s^{\prime}, i^{\prime}\right) \leq a, \\
\tilde{m}_{1 t}\left(a^{\prime}, m^{\prime}, s^{\prime}, i^{\prime}\right) \leq m, \\
\tilde{s}_{1 t}\left(a^{\prime}, m^{\prime}, s^{\prime}, i^{\prime}\right) \leq s, \\
i^{\prime} \leq i
\end{array}\right) \delta_{t} \mathbb{I}_{s^{\prime}>0} d t \tilde{z}_{1 t}\left(a^{\prime}, m^{\prime}, s^{\prime}, i^{\prime}\right) d F_{1, t-d t}\left(a^{\prime}, m^{\prime}, s^{\prime}, i^{\prime}\right) \\
& +\int \mathbb{I}\left(\begin{array}{l}
a^{\prime} \leq a, \\
\tilde{m}_{1 t}\left(a^{\prime}, m^{\prime}, s^{\prime}\right) \leq m, \\
\tilde{s}_{1 t}\left(a^{\prime}, m^{\prime}, s^{\prime}\right) \leq s, \\
i^{\prime} \leq i
\end{array}\right) \delta_{t} \mathbb{I}_{s^{\prime}>0} d t\left(1-\tilde{z}_{1 t}\left(a^{\prime}, m^{\prime}, s^{\prime}, i^{\prime}\right)\right) d F_{1, t-d t}\left(a^{\prime}, m^{\prime}, s^{\prime}, i^{\prime}\right) \\
& +\int \mathbb{I}\left(\begin{array}{l}
a^{\prime}+(1+h) s^{\prime} \leq a \\
\tilde{m}_{1 t}\left(a^{\prime}, m^{\prime}, s^{\prime}, i^{\prime}\right) \leq m, \\
\tilde{s}_{1 t}\left(a^{\prime}, m^{\prime}, s^{\prime}, i^{\prime}\right) \leq s, \\
i^{\prime} \leq i
\end{array}\right) \tilde{d}_{1 t}\left(a^{\prime}, m^{\prime}, s^{\prime}, i^{\prime}\right) d F_{1, t-d t}\left(a^{\prime}, m^{\prime}, s^{\prime}, i^{\prime}\right) \\
& +\lambda d t \int \mathbb{I}\left(\begin{array}{l}
a^{\prime} \leq a, \\
\tilde{i}_{I t}\left(a^{\prime}, m^{\prime}, s^{\prime}\right) \leq i, \\
\tilde{m}_{I t}\left(a^{\prime}, m^{\prime}, s^{\prime}\right) \leq m, \\
\tilde{s}_{I t}\left(a^{\prime}, m^{\prime}, s^{\prime}\right) \leq s
\end{array}\right) d F_{0, t-d t}\left(a^{\prime}, m^{\prime}, s^{\prime}\right) \\
& +\lambda d t \int \mathbb{I}\left(\begin{array}{l}
a^{\prime} \leq a, \\
\tilde{i}_{I t}\left(a^{\prime}, m^{\prime}, 0\right) \leq i, \\
\tilde{m}_{I t}\left(a^{\prime}, m^{\prime}, 0\right) \leq m, \\
\tilde{s}_{I t}\left(a^{\prime}, m^{\prime}, 0\right) \leq s
\end{array}\right) d F_{d, t-d t}\left(a^{\prime}, m^{\prime}\right)
\end{aligned}
$$

If $\omega_{t-d t}=0, F_{0 t}^{1}(\infty, \infty, \infty)=0, F_{d t}^{1}(\infty, \infty)=0, F_{1 t}^{1}(\infty, \infty, \infty, \infty)=0$, and 


$$
\begin{gathered}
d G_{0 t}(m)=-(\mu+\lambda) d t \int_{\left\{\tilde{m}\left(m^{\prime}\right) \leq m\right\}} d G_{0 t-d t}\left(m^{\prime}\right)+\eta d t \mathbb{I}\left\{\tilde{m}_{0 A} \leq m\right\} \\
d G_{1 t}(m, i)=-\pi d t \int_{\left\{\tilde{m}_{I 0}\left(m^{\prime}\right) \leq m\right\}} d G_{1, t-d t}\left(m^{\prime}, i\right)+\lambda d t \int \mathbb{I}\left\{\begin{array}{l}
\tilde{i}_{I 0}\left(m^{\prime}\right) \leq i, \\
\tilde{m}_{I 0}\left(m^{\prime}\right) \leq m
\end{array}\right\} d G_{0 t-d t}\left(m^{\prime}\right)
\end{gathered}
$$

If $\omega_{t-d t}=1$, then conditional on the $\omega_{t}=0$,

$$
\begin{aligned}
& \left.G_{0 t}(m)=\int \mathbb{I}_{\left\{m^{\prime} \leq m\right.}\right\}^{[1-(\mu+\lambda) d t] d F_{0, t-d t}\left(a^{\prime}, m^{\prime}, s^{\prime}\right)} \\
& \int \mathbb{I}\left\{m^{\prime} \leq m\right\}^{[1-(\mu+\lambda) d t] d F_{d, t-d t}\left(a^{\prime}, m^{\prime}\right)} \\
& +\eta d t \mathbb{I}\left\{\tilde{m}_{0 A}(w) \leq m\right\} \\
& G_{1 t}(m, i)=\int \mathbb{I}\left\{\begin{array}{c}
m^{\prime} \leq m, \\
i^{\prime} \leq i
\end{array}\right\}^{[1-(\mu+\pi) d t] d F_{1, t-d t}\left(a^{\prime}, m^{\prime}, s^{\prime}, i^{\prime}\right)} \\
& +\lambda d t \int \mathbb{I}\left\{\begin{array}{l}
\tilde{m}_{0 A}\left(m^{\prime}\right) \leq m, \\
\tilde{i}_{0 A}\left(m^{\prime}\right) \leq i
\end{array}\right\} d F_{0, t-d t}\left(a^{\prime}, m^{\prime}, s^{\prime}\right) \\
& +\lambda d t \int \mathbb{I}\left\{\begin{array}{l}
\tilde{m}_{0 A}\left(m^{\prime}\right) \leq m, \\
\tilde{i}_{0 A}\left(m^{\prime}\right) \leq i
\end{array}\right\} d F_{d, t-d t}\left(a^{\prime}, m^{\prime}\right)
\end{aligned}
$$

\section{B Efficiency}

Proof for Proposition 5.1: 
Proof.

$$
\begin{aligned}
& S_{t}=\max _{\left\{C_{\tau}, m_{\tau}, i_{\tau}\right\}_{\forall \tau \geq t}} \int_{t}^{\infty} C_{\tau} e^{-\rho(\tau-t)} d \tau, \\
& C_{\tau} d \tau+(\lambda d \tau) \frac{\eta}{\mu+\lambda} i_{\tau}+m_{\tau} \leq \int_{-\infty}^{\tau} \frac{\rho+\pi}{\pi} \theta i_{s}^{\alpha}(\pi d \tau) e^{-\pi(\tau-s)} \lambda \frac{\eta}{\mu+\lambda} d s \quad e^{-\rho(\tau-t)} \gamma_{\tau} \\
& \text { s.t. } \\
& +\int_{-\infty}^{\tau} a y \omega_{\tau}(\mu d \tau) e^{-\mu(\tau-s)} \eta d s+(\eta d \tau) M_{\tau}+m_{\tau-d \tau}, \\
& C_{\tau}, m_{\tau}, i_{\tau} \geq 0 \\
& \gamma_{c \tau}, \gamma_{l \tau}, \gamma_{m \tau}, \gamma_{i \tau}
\end{aligned}
$$

FOC

$$
\begin{aligned}
& C_{\tau}: \quad e^{-\rho(\tau-t)} d \tau-e^{-\rho(\tau-t)} \gamma_{\tau} d \tau+\gamma_{c \tau}=0 \\
& m_{\tau}: \quad-e^{-\rho(\tau-t)} \gamma_{\tau}+e^{-\rho(\tau+d \tau-t)} \gamma_{\tau+d \tau}+\gamma_{m \tau}=0 \\
& i_{\tau}: \quad-\lambda d \tau \frac{\eta}{\mu+\lambda} e^{-\rho(\tau-t)} \gamma_{\tau}+\int_{\tau}^{\infty} \theta \alpha i_{\tau}^{\alpha-1}(\rho+\pi) d \tau e^{-\pi(s-\tau)} \lambda \frac{\eta}{\mu+\lambda} e^{-\rho(s-t)} \gamma_{s} d s+\gamma_{i \tau}=0 \\
& -1+\theta \alpha i_{\tau}^{\alpha-1} \int_{\tau}^{\infty}(\rho+\pi) e^{-(\rho+\pi)(s-\tau)} d s=0 \\
& \theta \alpha i_{\tau}^{\alpha-1}=1
\end{aligned}
$$

Substituting the resource constraint to the objective function ...

$$
\begin{aligned}
C_{t}-\eta m_{t}+\lambda \frac{\eta}{\mu+\lambda} i_{t} & =\int_{-\infty}^{\tau}\left[\frac{\rho+\pi}{\pi} \theta i_{s}^{\alpha} \pi e^{-\pi(\tau-s)}\right] \lambda \frac{\eta}{\mu+\lambda} d s+\int_{-\infty}^{\tau} a \mu e^{-\mu(\tau-s)} \eta d s \\
& =\frac{\rho+\pi}{\pi} \theta i_{s}^{\alpha} \lambda \frac{\eta}{\mu+\lambda}+a \eta \\
C^{*}-\eta m^{*} & =\left[\frac{\rho+\pi}{\pi} \theta i^{* \alpha}-i^{*}\right] \frac{\lambda \eta}{\mu+\lambda}+a \eta
\end{aligned}
$$

\section{C the effect of collateral risk}

\section{C.1 Equilibrium with state-contingent collateralized debt contract and exoge- nous haircut}

The contract is contingent on liquidity arrival: At the date of borrowing, the borrower puts down $h$ units of collateral for each unit of consumption good she borrows; when the borrower has liquidity 
to repay the debt, the repayment is $1+R$, and if the borrower does not repay the debt, the lender will keep the collateral.

The borrower's expected payoff when she invests in a long-term project is

$$
\begin{aligned}
U\left(a_{0}, m, s\right) & =\max _{b} f(m+s+b)+\frac{\mu y}{\rho+\chi+\mu} a_{0}-\frac{(\mu+\pi)(1+R) b}{\rho+\chi+\mu+\pi} \\
\text { s.t. } 0 & \leq b \leq \frac{a_{0}}{(1+R) h}
\end{aligned}
$$

FOC:

$$
f^{\prime}(m+s+b)-\gamma_{1}-\gamma_{0}-\frac{(\mu+\pi)(1+R)}{\rho+\chi+\mu+\pi}=0
$$

If the optimal borrowing is such that $f^{\prime}(m+s+b)>\frac{(\mu+\pi)(1+R)}{\rho+\chi+\mu+\pi}$, then $b=\frac{a_{0}}{(1+R) h}$. Otherwise, $f^{\prime}(m+s+b)=\frac{(\mu+\pi)(1+R)}{\rho+\chi+\mu+\pi}$.

Assume that $\theta$ is high enough and $a_{0}$ and $m_{0}$ are small enough so that, $f^{\prime}(m+s+b)>\frac{(\mu+\pi)(1+R)}{\rho+\chi+\mu+\pi}$, or $f^{\prime}\left(m+s+\frac{a_{0}}{h}\right)>\frac{(\mu+\pi)(1+R)}{\rho+\chi+\mu+\pi}$, then,

$$
U\left(a_{0}, m, s\right)=f\left(m+s+\frac{a_{0}}{h}\right)+\left[\frac{\mu y}{\rho+\chi+\mu}-\frac{\mu+\pi}{(\rho+\chi+\mu+\pi) h}\right] a_{0}
$$

The value function of an agent before she finds her long-term project is

$$
\begin{aligned}
&(\rho+\mu+\chi+\lambda) V\left(a_{0}, m, s\right)=\mu\left(a_{0} y+m_{0}\right)+\chi \frac{\lambda}{\rho+\lambda} f(m)+(\mu+\pi) R s \\
&+\lambda\left\{f\left(m+s+\frac{a_{0}}{h}\right)+\left[\frac{\mu y}{\rho+\chi+\mu}-\frac{\mu+\pi}{(\rho+\chi+\mu+\pi) h}\right] a_{0}\right\} \\
&(\rho+\mu+\chi+\lambda) V\left(a_{0}, m, m_{0}-m\right)=\mu\left(a_{0} y+m_{0}\right)+\chi \frac{\lambda}{\rho+\lambda} f(m)+(\mu+\pi) R\left(m_{0}-m\right) \\
&+\lambda\left\{f\left(m_{0}+\frac{a_{0}}{h}\right)+\left[\frac{\mu y}{\rho+\chi+\mu}-\frac{(\mu+\pi)(1+R)}{(\rho+\chi+\mu+\pi) h}\right] a_{0}\right\}
\end{aligned}
$$

The optimal choice of portfolio implies that $\frac{d V\left(a_{0}, m, m_{0}-m\right)}{d m}=0$.

$$
R=\frac{\chi}{\mu+\pi} \frac{\lambda}{\rho+\lambda} f^{\prime}(m)
$$


The equilibrium is solved by the following system of equations:

$$
\begin{aligned}
R & =\frac{\chi}{\mu+\pi} \frac{\lambda}{\rho+\lambda} f^{\prime}(m), \\
\frac{m_{0}-m}{\mu+\lambda} & =\frac{\lambda}{\mu+\lambda} \frac{a_{0}}{(1+R) h} \frac{1}{\mu+\pi},
\end{aligned}
$$

the last equation being the market-clearing condition.

With the system of equations, the net supply to the market for the state-contingent contract, $\Gamma$, can be reduced to a function of storage holding $m$.

$$
\begin{gathered}
(\mu+\lambda) \Gamma(m)=m_{0}-m-\frac{\lambda}{\mu+\pi} \frac{a_{0}}{(1+R) h} \\
=m_{0}-m-\frac{\lambda}{\mu+\pi} \frac{a_{0}}{h} \frac{1}{1+\frac{\chi}{\mu+\pi} \frac{\lambda}{\rho+\lambda} f^{\prime}(m)} \\
\Gamma(0)=0 \text { and }(\mu+\lambda) \Gamma\left(m_{0}\right)=-\frac{\lambda}{\mu+\lambda} \frac{a_{0}}{h} \frac{1}{1+\frac{\chi}{\mu+\pi} \frac{\lambda}{\rho+\lambda} f^{\prime}\left(m_{0}\right)}<0 . \\
(\mu+\lambda) \Gamma^{\prime}(m)=-1+\frac{\lambda}{\mu+\pi} \frac{a_{0}}{h} \frac{\frac{\chi}{\mu+\pi} \frac{\lambda}{\rho+\lambda} f^{\prime \prime}(m)}{\left\{1+\frac{\chi}{\mu+\pi} \frac{\lambda}{\rho+\lambda} f^{\prime}(m)\right\}^{2}}<0
\end{gathered}
$$

So, if the equilibrium exists, it is unique.

\section{Comparative statics}

$$
\begin{aligned}
(\mu+\lambda) \frac{\partial \Gamma}{\partial \chi} & =\frac{\lambda}{\mu+\pi} \frac{a_{0}}{h} \frac{\frac{1}{\mu+\pi} \frac{\lambda}{\rho+\lambda} f^{\prime}(m)}{\left[1+\frac{\chi}{\mu+\pi} \frac{\lambda}{\rho+\lambda} f^{\prime}(m)\right]^{2}}>0 \\
(\mu+\lambda) \frac{\partial \Gamma}{\partial \pi} & =-\frac{\lambda}{\mu+\pi} \frac{a_{0}}{h} \frac{1}{1+\frac{\chi}{\mu+\pi} \frac{\lambda}{\rho+\lambda} f^{\prime}(m)}\left\{-\frac{1}{\mu+\pi}-\frac{-\frac{\chi}{(\mu+\pi)^{2}} \frac{\lambda}{\rho+\lambda} f^{\prime}(m)}{1+\frac{\chi}{\mu+\pi} \frac{\lambda}{\rho+\lambda} f^{\prime}(m)}\right\} \\
& =\frac{\lambda}{(\mu+\pi)^{2}} \frac{a_{0}}{h} \frac{1}{1+\frac{\chi}{\mu+\pi} \frac{\lambda}{\rho+\lambda} f^{\prime}(m)} \frac{1}{1+\frac{\chi}{\mu+\pi} \frac{\lambda}{\rho+\lambda} f^{\prime}(m)} \\
& >0
\end{aligned}
$$




\section{Characterization of equilibrium with debt rollover}

\section{D.1 The problem of agents with a long-term project}

Given the price of assets at fire sale, implied by $h$, the maximum amount of borrowing is $\frac{a_{0}}{h}$. At the moment of default, the borrower's continuation value is $f(i)+\frac{\mu}{\rho+\mu+\chi}\left(a-a_{0}\right)$. For a borrower with $a$ assets decides to default when she puts down $a_{0}$ units of asset as collateral, the value function can be solved by the following differential equation. It is easy to verify that an agent will hold zero storage after her long-term investment. So, we denote $W(a, b, 0, i)=\max _{0 \leq a_{0} \leq a} \tilde{W}\left(a, b, a_{0}, i\right)$

$$
\begin{aligned}
\rho \tilde{W}\left(a, b, a_{0}, i\right) & =\pi\left[\frac{\rho+\pi}{\pi} f(i)+\frac{\mu}{\rho+\mu+\chi} y a-b-\tilde{W}\left(a, b, a_{0}, i\right)\right] \\
& +\chi\left[f(i)-W\left(a, b, a_{0}, i\right)\right] \\
& +\mu\left[f(i)+y a-b-W\left(a, b, a_{0}, i\right)\right]+\frac{\partial \tilde{W}\left(a, b, a_{0}, i\right)}{\partial b} b R, \\
\tilde{W}\left(a, \frac{a_{0}}{h}, a_{0}, i\right) & =f(i)+\frac{\mu y}{\rho+\mu+\chi}\left(a-a_{0}\right),
\end{aligned}
$$

where $\tilde{W}\left(a, \frac{a_{0}}{1+h}, a_{0}, i\right)$ is the continuation when she defaults.

\section{Lemma D.1.}

$$
\begin{aligned}
\tilde{W}\left(a, b, a_{0}, i\right) & =\left[\frac{\mu+\pi-\chi \tau}{\rho+\chi+\mu+\pi-R} \frac{1}{h}-\frac{\mu}{\rho+\mu+\chi} y\right] a_{0}\left(\frac{h b}{a_{0}}\right)^{(\rho+\chi+\mu+\pi) / R} \\
& -\frac{\mu+\pi-\chi \tau}{\rho+\chi+\mu+\pi-R} b+f(i)+\frac{\mu}{\rho+\mu+\chi} y a
\end{aligned}
$$

Proof.

$$
(\rho+\chi+\mu+\pi) \tilde{W}\left(a, b, a_{0}, i\right)=(\rho+\chi+\mu+\pi) f(i)-(\mu+\pi) b+\mu \frac{\rho+\mu+\chi+\pi}{\rho+\mu+\chi} y a+\frac{\partial \tilde{W}\left(a, b, a_{0}, I\right)}{\partial b} b R
$$

Guess $\tilde{W}\left(a, b, a_{0}, i\right)=C_{0} b^{(\rho+\chi+\mu+\pi) / R}+C_{1} b+C_{2}\left(f(i)+\frac{\mu}{\rho+\mu+\chi} y a\right)+C_{3}$. Then $\frac{\partial \tilde{W}\left(a, b, a_{0}, I\right)}{\partial b}=$ $\frac{\rho+\chi+\mu+\pi}{R} C_{0} b^{(\rho+\chi+\mu+\pi-R) / R}+C_{1}$.

$$
\begin{aligned}
& (\rho+\chi+\mu+\pi)\left[C_{0} b^{(\rho+\chi+\mu+\pi) / R}+C_{1} b+C_{2}\left(f(I)+\frac{\mu}{\rho+\mu+\chi} y a\right)+C_{3}\right] \\
= & (\rho+\chi+\mu+\pi) f(I)-(\mu+\pi-\chi \tau) b+\mu \frac{\rho+\mu+\chi+\pi}{\rho+\mu+\chi} y a \\
& +b R\left[\frac{\rho+\chi+\mu+\pi}{R} C_{0} b^{(\rho+\chi+\mu+\pi-R) / R}+C_{1}\right]
\end{aligned}
$$




$$
\begin{aligned}
& (\rho+\chi+\mu+\pi) C_{1}=R C_{1}-(\mu+\pi-\chi \tau) \\
& (\rho+\chi+\mu+\pi) C_{2}=(\rho+\chi+\mu+\pi) \\
& (\rho+\chi+\mu+\pi) C_{3}=0
\end{aligned}
$$

$$
C_{1}=-\frac{\mu+\pi-\chi \tau}{\rho+\chi+\mu+\pi-R}, C_{2}=1, C_{3}=0 .
$$

Therefore, $\tilde{W}\left(a, b, a_{0}, I\right)=C_{0} b^{(\rho+\chi+\mu+\pi) / R}-\frac{\mu+\pi-\chi \tau}{\rho+\chi+\mu+\pi-R} b+f(i)+\frac{\mu}{\rho+\mu+\chi} y a$. Since $\tilde{W}\left(a, \frac{a_{0}}{1+h}, a_{0}, i\right)=$ $f(i)+\frac{\mu y}{\rho+\mu+\chi}\left(a-a_{0}\right)$, we have

$$
\begin{aligned}
C_{0}\left(\frac{a_{0}}{h}\right)^{(\rho+\chi+\mu+\pi) / R}- & \frac{\mu+\pi}{\rho+\chi+\mu+\pi-R} \frac{a_{0}}{h}+f(i)+\frac{\mu}{\rho+\mu+\chi} y a=f(i)+\frac{\mu y}{\rho+\mu+\chi}\left(a-a_{0}\right) \\
C_{0} & =\left[\frac{\mu+\pi}{\rho+\chi+\mu+\pi-R} \frac{1}{h}-\frac{\mu}{\rho+\mu+\chi} y\right] a_{0}\left(\frac{a_{0}}{h}\right)^{-(\rho+\chi+\mu+\pi) / R} \\
\tilde{W}\left(a, b, a_{0}, i\right) & =\left[\frac{\mu+\pi}{\rho+\chi+\mu+\pi-R} \frac{1}{h}-\frac{\mu}{\rho+\mu+\chi} y\right] a_{0}\left(\frac{h b}{a_{0}}\right)^{(\rho+\chi+\mu+\pi) / R} \\
& -\frac{\mu+\pi}{\rho+\chi+\mu+\pi-R} b+f(i)+\frac{\mu}{\rho+\mu+\chi} y a
\end{aligned}
$$

Lemma D.2. The partial derivative of the value function is

$$
\begin{aligned}
\frac{\partial \tilde{W}\left(a, b, a_{0}, i\right)}{\partial y} & =\frac{\mu}{\rho+\mu+\chi}\left[a-a_{0}\left(\frac{h b}{a_{0}}\right)^{(\rho+\chi+\mu+\pi) / R}\right] \\
\frac{\partial \tilde{W}\left(a, b, a_{0}, i\right)}{\partial a_{0}} & =\left[\frac{\mu}{\rho+\mu+\chi} y-\frac{\mu+\pi}{\rho+\chi+\mu+\pi-R} \frac{1}{h}\right] \frac{\rho+\chi+\mu+\pi-R}{R}\left(\frac{h b}{a_{0}}\right)^{(\rho+\chi+\mu+\pi) / R} \\
\frac{\partial \tilde{W}\left(a, b, a_{0}, i\right)}{\partial a} & =\frac{\mu}{\rho+\mu+\chi} y \\
\frac{\partial \tilde{W}\left(a, b, a_{0}, i\right)}{\partial b} & =\left[\frac{\mu}{\rho+\mu+\chi} y h-\frac{\mu+\pi}{\rho+\chi+\mu+\pi-R}\right] \frac{\rho+\chi+\mu+\pi}{R}\left[-\left(\frac{h b}{a_{0}}\right)^{(\rho+\chi+\mu+\pi-R) / R}\right] \\
& -\frac{\mu+\pi}{\rho+\chi+\mu+\pi-R} \\
\frac{\partial \tilde{W}\left(a, b, a_{0}, i\right)}{\partial i} & =f^{\prime}(i)
\end{aligned}
$$

From Lemma D.2, we can see that the borrower will roll over her debt up to the debt limit as long as $\frac{\mu}{\rho+\mu+\chi} y-\frac{\mu+\pi}{\rho+\chi+\mu+\pi-R} \frac{1}{h}>0$. And, in this case, $W(a,-b, i)=\tilde{W}(a, b, a, i)$. 
Lemma D.3. agents

- will borrow against all their asset if $\frac{\mu}{\rho+\mu+\chi} y-\frac{\mu+\pi}{\rho+\chi+\mu+\pi-R} \frac{1}{h}>0$ or $h>\frac{\mu+\pi}{\rho+\chi+\mu+\pi-R} \frac{\rho+\mu+\chi}{\mu y}$.

- will not borrow if $h<\frac{\mu+\pi}{\rho+\chi+\mu+\pi-R} \frac{\rho+\mu+\chi}{\mu y}$

- are indifferent between borrowing or not if $h=\frac{\mu+\pi}{\rho+\chi+\mu+\pi-R} \frac{\rho+\mu+\chi}{\mu y}$.

\section{D.2 The problem of agents when they find a long-term project}

Next, I consider the optimization problem at the moment the agent finds an investment opportunity.

$$
U(a, m, s)=\max _{c \geq 0,0 \leq b \leq \frac{a_{0}}{1+h}} c+W(a,-b, s+m-c+b)
$$

The first-order condition of the problem is

$$
\begin{aligned}
\frac{d W(a,-b, s+m-c+b)}{d b} & =0 \\
\frac{\partial}{\partial b} W+\frac{\partial}{\partial i} W & =0 .
\end{aligned}
$$

From the first-order condition we have the following lemma.

Lemma D.4. The optimal choice of project investment and initial borrowing of an agent with portfolio $(a, s, m)$ is solved by equation

$$
\left(\frac{h b}{a}\right)^{(\rho+\chi+\mu+\pi-R) / R}=\frac{R}{\rho+\chi+\mu+\pi} \frac{f^{\prime}(s+b)-\frac{\mu+\pi}{\rho+\chi+\mu+\pi-R}}{\frac{\mu}{\rho+\mu+\chi} y h-\frac{\mu+\pi}{\rho+\chi+\mu+\pi-R}}
$$

Let $\hat{b}=\frac{h b}{a+h s^{\prime}} . b=\frac{a+h s^{\prime}}{h} \hat{b}, s-s^{\prime}+b=s+\frac{a}{h} \hat{b}-(1-\hat{b}) s^{\prime}$. Let

$$
\begin{aligned}
\Gamma= & {\left[\frac{\mu}{\rho+\mu+\chi} y h-\frac{\mu+\pi}{\rho+\chi+\mu+\pi-R}\right] \frac{\rho+\chi+\mu+\pi}{R} \hat{b}^{(\rho+\chi+\mu+\pi-R) / R} } \\
& -\left[f^{\prime}\left(s+\frac{a}{h} \hat{b}-(1-\hat{b}) s^{\prime}\right)-\frac{\mu+\pi}{\rho+\chi+\mu+\pi-R}\right]
\end{aligned}
$$

$$
\begin{aligned}
\frac{\partial \Gamma}{\partial s^{\prime}} & =(1-\hat{b}) f^{\prime \prime}\left(s+\frac{a}{h} \hat{b}-(1-\hat{b}) s^{\prime}\right)<0 \\
\frac{\partial \Gamma}{\partial \hat{b}} & =\left[\frac{\mu}{\rho+\mu+\chi} y h-\frac{\mu+\pi}{\rho+\chi+\mu+\pi-R}\right] \frac{\rho+\chi+\mu+\pi}{R} \frac{\rho+\chi+\mu+\pi-R}{R} \hat{b}^{(\rho+\chi+\mu+\pi-2 R) / R} \\
& -\left(\frac{a}{h}+s^{\prime}\right) f^{\prime \prime}\left(s+\frac{a}{h} \hat{b}-(1-\hat{b}) s^{\prime}\right)>0
\end{aligned}
$$

Then, from the Implicit Function Theorem, we have the following result: 
Lemma D.5. Counterparty default increases the default probability of lenders in the future

$$
\frac{d \hat{b}}{d s^{\prime}}>0
$$

Since default probability is an increasing function of $\hat{b}$, we know from this lemma that counterparty default that transforms liquid funding to collateral assets will increase the default probability when the agent starts borrowing.

\section{D.3 The problem of agents waiting for an investment opportunity}

In the stationary environment, the value functions of agents waiting for their investment opportunities, given the optimal portfolio choice on storage $m$ and lending $s$, can be written as follows:

$$
\begin{aligned}
(\rho+\mu+\chi+\lambda+\delta) V(a, m, s) & =s R+\mu(y a+s+m)+\delta V^{d}(a+h s, m)+\chi V^{A}(m)+\lambda U(a, m, s) \\
(\rho+\mu+\chi+\lambda) V^{d}(a+h s, m) & =\mu[y(a+h s)+m]+\chi V^{A}(m)+\lambda U(a+h s, m, 0) . \\
(\rho+\lambda) V^{A}(m) & =\lambda \theta m^{\alpha}
\end{aligned}
$$

Lemma D.6. The following condition must be satisfied in equilibrium:

$$
\mu(y h-1) s=s R+\lambda[U(a, s, m)-U(a+h s, 0, m)]
$$

Proof. Suppose, instead, that $V^{d}(a+h s, m)>V(a, m, s)$. Then lenders will default on the loan by keeping the collateral. So, $V^{d}(a+h s, m) \leq V^{d}(a, m, s)$. Suppose, $V^{d}(a+h s, m)<V(a, m, s)$. Then, lenders won't be willing to lend to the defaulting borrowers when they observe that the borrowers are going to default. Rollover is not possible.

Given the value functions, the optimal portfolio choice is solved by the following problem:

$$
\begin{array}{r}
\max _{s, m \in \mathbb{R}_{+}} V(a, m, s) \\
\text { s.t.s }+m \leq m_{0}
\end{array}
$$




\section{E Equilibrium dynamics with a constant $\chi$}

Given the initial condition, the distribution of lenders and borrowers, we need to solve the sequence of default $\operatorname{rate} \delta_{t}$, interest rate $R_{t}$, haircut $h_{t}$, and the optimal portfolio choice of active lenders between repo lending $s_{t}$ and storage $m_{t}$.

\section{Active lenders' portfolio choice}

Given the value functions,

$$
\begin{aligned}
& s R_{t} d t+\tilde{c}+\mu d t(a y+\tilde{m}+\tilde{s})+\delta_{t} d t e^{-\rho d t} V_{t+d t}\left(a+h_{t} \tilde{s}, \tilde{m}, 0\right) \\
& V_{t}(a, m, s)=\max _{\tilde{c}, \tilde{m}, \tilde{s}}+\chi d t \frac{\lambda}{\rho+\lambda} f(\tilde{m})+\lambda d t \hat{W}_{t}(a, \tilde{m}, \tilde{s}) \\
&+\left[1-\left(\mu+\delta_{t}+\chi+\lambda\right) d t\right] e^{-\rho d t} V_{t+d t}(a, \tilde{m}, \tilde{s}) \\
& \text { s.t. } \tilde{c}+\tilde{m}+\tilde{s} \leq m+s \\
& \tilde{c}, \tilde{m}, \tilde{s} \geq 0
\end{aligned}
$$

We focus on the parameter space where consumption allocation before agents exit the market is always 0. Thus, $\tilde{c}=0$, and $m+s=\tilde{m}+\tilde{s}=m_{0}$, Since $m_{0}$ is a constant, $\frac{\partial V_{t}(a, m, s)}{\partial s}=R_{t} d t$, $U_{t}\left(a, \tilde{m}, m_{0}-\tilde{m}\right)$ does not depend on $\tilde{m}$ given $w$, and $\tilde{m}$ is solved by the following problem:

$$
\max _{0 \leq \tilde{m} \leq m_{0}} \delta_{t} d t e^{-\rho d t} V_{t+d t}\left(a+h_{t}\left(m_{0}-\tilde{m}\right), \tilde{m}, 0\right)+\chi d t \frac{\lambda}{\rho+\lambda} f(\tilde{m})-R_{t} d t \tilde{m}
$$

FOC

$$
\begin{gathered}
\delta_{t}\left(-h_{t} \frac{\partial}{\partial a}+\frac{\partial}{\partial m}\right) V_{t+d t}\left(a+h_{t}\left(m_{0}-\tilde{m}\right), \tilde{m}, 0\right)+\chi \frac{\lambda}{\rho+\lambda} f^{\prime}(\tilde{m})-R_{t}+\gamma_{\tilde{m} \geq 0}-\gamma_{\tilde{m} \leq w}=0 \\
\frac{\partial}{\partial a} V_{t+d t}^{d}\left(a+h_{t}\left(m_{0}-\tilde{m}\right), \tilde{m}\right)=\int_{0}^{\infty}\left[\mu y+\lambda \frac{d}{d a} U_{t+s}\left(a^{\prime}, m^{\prime}, 0\right)\right] e^{-(\mu+\lambda+\chi+\rho) s} d s \\
\frac{d}{d a} U_{t}(a, m, 0) \\
=\int_{0}^{T_{t}(b)}\left[\mu y+\pi \frac{\mu y}{\rho+\chi+\mu}\right] e^{-(\chi+\pi+\mu+\rho) \tau} d \tau \\
=\frac{\mu y}{\rho+\chi+\mu}\left[1-e^{-(\rho+\pi+\mu+\chi) T_{t}(b)}\right]
\end{gathered}
$$




$$
\begin{aligned}
& \frac{\partial}{\partial a} V_{t+d t}^{d}\left(a+h_{t}\left(m_{0}-\tilde{m}\right), \tilde{m}\right) \\
= & \int_{0}^{\infty}\left[\mu y+\lambda \frac{\mu y}{\rho+\chi+\mu}\left(1-e^{-(\rho+\pi+\mu+\chi) T_{t+s}\left(b_{t}\left(a+\left(1+h_{t}\right)(w-\tilde{m}), \tilde{m}\right)\right)}\right)\right] e^{-(\mu+\lambda+\chi+\rho) s} d s \\
& \frac{\partial}{\partial m} V_{t+d t}^{d}\left(a+h_{t}\left(m_{0}-\tilde{m}\right), \tilde{m}\right) \\
= & \int_{0}^{\infty}\left[\mu+\lambda \frac{\partial}{\partial m} U_{t+s}\left(a+h_{t}(w-\tilde{m}), \tilde{m}, 0\right)+\chi \frac{\lambda}{\rho+\lambda} f^{\prime}(\tilde{m})\right] e^{-(\mu+\lambda+\chi+\rho) s} d s \\
= & \frac{\mu+\chi \frac{\lambda}{\rho+\lambda} f^{\prime}(\tilde{m})}{\mu+\lambda+\chi+\rho}+\lambda \int_{0}^{\infty} f^{\prime}\left(\tilde{m}+b_{t+s}\left(a+h_{t}(w-\tilde{m}), \tilde{m}\right)\right) e^{-(\mu+\lambda+\chi+\rho) s} d s
\end{aligned}
$$

\section{Haircut and indifference condition}

$$
\begin{aligned}
V_{t}^{d}(a, m) & =\int_{0}^{\infty}\left[\mu(a y+m)+\lambda U_{t+s}(a, m, 0)+\chi \frac{\lambda}{\rho+\lambda} f(m)\right] e^{-(\mu+\lambda+\chi+\rho) s} d s \\
& =\frac{\mu(a y+m)+\chi \frac{\lambda}{\rho+\lambda} f(m)}{\mu+\lambda+\chi+\rho}+\int_{0}^{\infty} \lambda U_{t+s}(a, m, 0) e^{-(\mu+\lambda+\chi+\rho) s} d s \\
V_{t}\left(a, \hat{m}_{t}, \hat{s}_{t}\right) & =\int_{0}^{\infty}\left[\begin{array}{l}
\hat{s}_{t+\tau} R_{t+\tau}+\delta_{t+\tau} V_{t+\tau}^{d}\left(a+h_{t+\tau} \hat{s}_{t+\tau}, \hat{m}_{t+\tau}\right)+\mu\left(a y+m_{0}\right) \\
+\chi \frac{\lambda}{\rho+\lambda} f\left(\hat{m}_{t+\tau}\right)+\lambda U_{t+\tau}\left(a, m_{0}\right)
\end{array}\right] \\
& e^{-\int_{0}^{\tau} \delta_{t+u} d u-(\mu+\chi+\lambda+\rho) \tau} d \tau
\end{aligned}
$$

Haircut must be such that, given the optimal choice $\left(\hat{m}_{t}, \hat{s}_{t}\right)$,

$$
V_{t}\left(a, \hat{m}_{t}, \hat{s}_{t}\right)=V_{t}^{d}\left(a+h_{t} \hat{s}_{t}, m_{t}\right)
$$

\section{Initial borrowing of investors with LT projects}

$\begin{array}{ll}U_{t}(a, m, s)=\max _{t} s d t+f(m+s+b) & \\ 0 \leq b \leq \frac{a}{h_{t}} & +\int_{0}^{T_{t}(b)}\left[\chi \cdot 0+\mu\left(a y-b e^{\int_{0}^{\tau} R_{t+s} d s}\right)+\pi\left(\frac{\mu a y}{\rho+\mu+\chi}-b e^{\int_{0}^{\tau} R_{t+s} d s}\right)\right] e^{-(\chi+\mu+\pi+\rho) \tau} d \tau\end{array}$

where $T_{t}(b)=\inf \left\{\tau: b e^{\int_{0}^{\tau} R_{t+s} d s} h_{t+\tau}=a\right\}$. The maximization problem is equivalent to the following problem: 


$$
\begin{array}{ll}
\max _{0 \leq b \leq \frac{a}{1+h_{t}}} & f(m+s+b)+\int_{0}^{T_{t}(b)} \frac{\rho+\mu+\chi+\pi}{\rho+\mu+\chi} \mu a y e^{-(\chi+\mu+\pi+\rho) \tau} d \tau \\
T_{t}(b) & (\mu+\pi) e^{\int_{0}^{\tau} R_{t+s} d s} e^{-(\chi+\mu+\pi+\rho) \tau} d \tau
\end{array}
$$

A sufficient condition for equation $b e^{\int_{0}^{\tau} R_{t+s} d s}=\frac{a}{h_{t+\tau}}$ to have at most one solution is that $e^{\int_{0}^{\tau} R_{t+s} d s} h_{\tau}$ is monotonically increasing. $e^{\int_{0}^{\tau} R_{t+s} d s}\left[R_{t+\tau} h_{t+\tau}+\dot{h}_{t+\tau}\right]>0$.

$$
\frac{\partial T_{t}(b)}{\partial b}=-\frac{h_{t+\tau}}{b\left[R_{t+\tau} h_{t+\tau}+\dot{h}_{t+\tau}\right]}
$$

\section{Market-clearing condition}

The density of deactivated lenders with portfolio $\left(a+s_{\tau}\left(1+h_{\tau}\right), m_{\tau}, 0\right)$ is $\delta_{\tau} n_{\tau}^{0} e^{-(\mu+\lambda)(t-\tau)}$. The measure of active lenders at $t$ is denoted $n_{t}^{0}$.

$$
\begin{aligned}
\text { Demand }_{t} & =\int_{0}^{\infty} \int_{0}^{\infty} \lambda \delta_{t-\tau-s} n_{t-\tau-s}^{1} e^{-(\mu+\lambda) s} b_{t-\tau-s}\left(a+s_{t-\tau-s} h_{t-\tau-s}, m_{t-\tau-s}, 0\right) e^{(R-\pi-\mu) \tau} \\
& \mathbb{I}\left\{\tau \leq T_{t-\tau}\left(b_{t-\tau-s}\left(a+s_{t-\tau-s} h_{t-\tau-s}, m_{t-\tau-s}, 0\right)\right)\right\} d s d \tau \\
& +\int_{0}^{\infty} \lambda n_{t-\tau}^{1} b_{t-\tau}\left(a, m_{0}, 0\right) e^{(R-\pi-\mu) \tau} \mathbb{I}\left\{\tau \leq T_{t-\tau}\left(b_{t-\tau}\left(a, m_{0}, 0\right)\right)\right\} d \tau
\end{aligned}
$$

$$
\text { Supply }_{t}=n_{t}^{1} \hat{s}_{t}
$$

\section{Default rate}

Updating $\delta_{t}$ depends on the measure of demand from borrowers and the flow of demand from defaulting borrowers.

$$
\delta_{t}=\frac{\text { Demand of defaulting } \text { borrower }_{t}}{\text { Demand }_{t}}
$$

The distribution of the lender's portfolio, $F(a, m, s)$, a function of timing of counterparty default. $n_{t}^{1}=\int_{0}^{\infty} \eta e^{-(\mu+\lambda) \tau-\int_{0}^{\tau} \delta_{t-s} d s} d \tau$. The measure of agents in the default cohort $\tau(\tau<t)$ at moment $t$ is $\delta_{\tau} n_{\tau}^{1} e^{-(\mu+\lambda)(t-\tau)}$. And agents in the default cohort $\tau$ have portfolio, $\left(a+s_{\tau}\left(1+h_{\tau}\right), m_{\tau}, 0\right)$. 


\section{Numerical algorithm to compute the transition path}

Suppose that the shock to expectation arrives at $t=0$.

1. Guess a sequence of interest rate, haircut and default rate, $\left\{R_{t}, h_{t}, \delta_{t}\right\}_{\forall t \geq 0}$.

2. Given the sequence, $\left\{R_{t}, h_{t}, \delta_{t}\right\}_{\forall t \geq 0}$, solve for the policy functions and value functions of agents on the transition path.

3. Given the $h_{0}$, solve for the mass of initial default. And then, given the policy function of agents, solve the distribution of agents along the transition path.

4. Given the distributions of agents and the policy functions, update the default rate of borrowers.

5. Given the distributions of agents and the policy functions, solve for the net demand of repo borrowing. Update the interest rate according to the net demand of repo borrowing.

6. Given the value functions of agents, update haircut.

7. Go back to step 2 with the updated sequence of interest rate, haircut and default rate, until convergence. 